OPEN ACCESS

Edited by:

Urszula Krzych,

Walter Reed Army Institute of

Research, United States

Reviewed by:

Tobias L. Lenz,

Max Planck Institute for Evolutionary

Biology, Germany

Irfan Zaidi,

National Institutes of Health (NIH),

United States

*Correspondence:

David Requena

drequena@rockefeller.edu

Obert Marín-Sánchez

omarins@unmsm.edu.pe

${ }^{\dagger}$ These authors have contributed equally to this work

Specialty section

This article was submitted to Vaccines and Molecular Therapeutics,

a section of the journal

Frontiers in Immunology

Received: 15 May 2020

Accepted: 24 July 2020

Published: 03 September 2020

Citation:

Requena $D$, Médico A, Chacón RD,

Ramirez M and Marín-Sánchez $O$

(2020) Identification of Novel Candidate Epitopes on SARS-CoV-2

Proteins for South America: A Review

of HLA Frequencies by Country.

Front. Immunol. 11:2008.

doi: 10.3389/fimmu.2020.02008

\section{Identification of Novel Candidate Epitopes on SARS-CoV-2 Proteins for South America: A Review of HLA Frequencies by Country}

\author{
David Requena ${ }^{1 * t}$, Aldhair Médico ${ }^{2 \dagger}$, Ruy D. Chacón ${ }^{3}$, Manuel Ramírez ${ }^{4}$ and \\ Obert Marín-Sánchez ${ }^{5 *}$
}

1 Laboratory of Cellular Biophysics, The Rockefeller University, New York, NY, United States, ${ }^{2}$ Laboratorio de Bioinformática, Biología Molecular y Desarrollos Tecnológicos, Laboratorios de Investigación y Desarrollo, Facultad de Ciencias y Filosofía, Universidad Peruana Cayetano Heredia, Lima, Peru, ${ }^{3}$ Departamento de Patologia, Faculdade de Medicina Veterinária e Zootecnia, Programa Interunidades em Biotecnologia, Universidade de São Paulo, São Paulo, Brazil, ${ }^{4}$ Unidad de Bioinformática, Centro de Investigaciones Tecnológicas, Biomédicas y Medioambientales, Lima, Peru, ${ }^{5}$ Departamento Académico de Microbiología Médica, Facultad de Medicina, Universidad Nacional Mayor de San Marcos, Lima, Peru

Coronavirus disease (COVID-19), caused by the virus SARS-CoV-2, is already responsible for more than 4.3 million confirmed cases and 295,000 deaths worldwide as of May 15, 2020. Ongoing efforts to control the pandemic include the development of peptide-based vaccines and diagnostic tests. In these approaches, HLA allelic diversity plays a crucial role. Despite its importance, current knowledge of HLA allele frequencies in South America is very limited. In this study, we have performed a literature review of datasets reporting HLA frequencies of South American populations, available in scientific literature and/or in the Allele Frequency Net Database. This allowed us to enrich the current scenario with more than 12.8 million data points. As a result, we are presenting updated HLA allelic frequencies based on country, including 91 alleles that were previously thought to have frequencies either under $5 \%$ or of an unknown value. Using alleles with an updated frequency of at least $\geq 5 \%$ in any South American country, we predicted epitopes in SARS-CoV-2 proteins using NetMHCpan (I and II) and MHC flurry. Then, the best predicted epitopes (class-I and -II) were selected based on their binding to South American alleles (Coverage Score). Class II predicted epitopes were also filtered based on their three-dimensional exposure. We obtained 14 class-I and four class-II candidate epitopes with experimental evidence (reported in the Immune Epitope Database and Analysis Resource), having good coverage scores for South America. Additionally, we are presenting $13 \mathrm{HLA}-\mathrm{I}$ and $30 \mathrm{HLA}$-II novel candidate epitopes without experimental evidence, including 16 class-II candidates in highly exposed conserved areas of the NTD and RBD regions of the Spike protein. These novel candidates have even better coverage scores for South America than those with experimental evidence. Finally, we show that recent similar studies presenting candidate epitopes also predicted some of our candidates but discarded them in the selection process, resulting in candidates with suboptimal coverage for South America. In conclusion, the candidate epitopes presented provide valuable information for the development of 
epitope-based strategies against SARS-CoV-2, such as peptide vaccines and diagnostic tests. Additionally, the updated HLA allelic frequencies provide a better representation of South America and may impact different immunogenetic studies.

\section{Keywords: allele frequency, HLA, literature review, South America, epitope, immunoinformatics, SARS-CoV-2, COVID-19}

\section{INTRODUCTION}

The novel virus Severe Acute Respiratory Syndrome Coronavirus 2 (SARS-CoV-2) $(1,2)$ is the first member of the Betacoronavirus genus to reach pandemic status (3). This virus probably originated in bats and infects humans with the participation of an intermediate host (4-7), like its two highly humaninfective relatives, SARS-CoV $(8,9)$ and MERS-CoV (10). It causes Coronavirus Disease 2019 (COVID-19), whose clinical symptoms include fever, cough, fatigue, sputum production, and difficulty breathing $(11,12)$. Transmission is mostly human-tohuman through respiratory droplets and direct contact, carrying infectious virions to the nose, mouth, and eyes $(13,14)$. It has spread to 216 countries, resulting in more than 4.3 million confirmed cases and 295,000 deaths worldwide as of May 15, 2020 (15). It has an estimated basic reproductive number $\left(R_{0}\right)$ of 2.24-3.58 (16).

SARS-CoV-2, as with other Coronaviruses, is characterized by a high recombination frequency and mutation rate, in addition to a relatively large and sophisticated genetic machinery compared to other RNA viruses. At the $5^{\prime}$ end of the genome, the cleavable polyprotein ab (ORF1ab) is processed into 16 non-structural proteins (NSPs). They are involved in the viral replication and assembly process, as well as in immune evasion $(17,18)$. At the $3^{\prime}$ end, the structural proteins Spike (S), envelope (E), membrane $(\mathrm{M})$, and nucleocapsid $(\mathrm{N})$ are interspersed by the accessory proteins ORF 3a, 6, 7a, 7b, 8, and $10(19,20)$. A key factor in viral attachment and entry is the receptor-binding domain (RBD), located in the subunit 1 (S1) of the S protein. This binds strongly to the angiotensin-converting enzyme 2 (ACE2) receptors $(21$, 22). Other possible receptors, like CD209L (23), CD147 (24), and the protease TMPRSS2 (25), could also participate in the viral entry and processing.

Post-translational modifications (PTMs) are covalent modifications that regulate protein functions. In coronaviruses, they are required for a successful viral cycle. Glycosylation and palmitoylation of $\mathrm{S}$ and $\mathrm{E}$ proteins are fundamental in terms of stability, enzymatic activity, subcellular localization, and protein interaction (26-29). Similarly, glycosylation of the $\mathrm{M}$ protein $(30,31)$, phosphorylation, and ribosylation of the $\mathrm{N}$ protein $(32,33)$, as well as other PTMs in nonstructural and accessory proteins, can play a determinant role in the viral cycle $(34,35)$. Considering the relevant role

\footnotetext{
Abbreviations: AFNDB, Allele Frequency Net Database; COVID-19, Coronavirus Disease 2019; CS, Coverage Score; GISAID, Global Initiative on Sharing All Influenza Data database; HLA, Human Leukocyte Antigen; IEDB, Immune Epitope Database and Analysis Resource; PDB, Protein Data Bank; PTM, Posttranslational modifications; SARS-CoV-2, Severe Acute Respiratory Syndrome Coronavirus 2; WAF, Weighted Allele Frequency.
}

of PTMs and the complex composition of N-glycans, it was proposed that inhibition with N-butyl-deoxynojirimycin (NB-DNJ) (35) or the addition of carbohydrate-binding agents (CBAs) could be considered as therapeutic strategies against SARS-CoV infections (36). Nitric Oxide (NO) and its derivatives have been shown to inhibit SARS-CoV replication by reducing the palmitoylation on the nascent Spike protein, affecting the receptor binding. It also affects viral RNA production in the early steps of replication, potentially due to an effect on the ORF1a-encoded cysteine proteases (37).

Effective methods to control the pandemic include the development of vaccines and diagnostic tests. The fast release of complete SARS-CoV-2 genomes boosted the development of molecular diagnostic methods, resulting in an increasing portfolio of nucleic acid approaches like RT-qPCR (38-40), serological-based approaches like ELISA (41, 42), immunochromatographic panels based on antibodies IgM/IgG (43) or antigens (44), and hybrid systems in Point-of-Care devices, consisting of viral genome pre-amplification followed by a cleavage assay in a lateral flow system (45).

Vaccine development efforts are undergoing worldwide. There are 110 prophylactic vaccine candidates as of May 15, 2020. Three of them are based on live-attenuated virus, seven on inactivated virus, 27 on viral vectors (12 replicating and 15 nonreplicating), 26 on nucleic acids (10 using DNA and 16 RNA), 38 on recombinant proteins, six on Virus-Like Particles (VLP), and three unknown $(46,47)$. Some vaccines have already moved to a clinical phase. There are six in Phase I: Pathogen-specific aAPC (NCT04299724, Shenzhen Geno-Immune Medical Institute, China), Recombinant Novel Coronavirus Vaccine (Adenovirus Type 5 Vector) (NCT04313127, CanSino Biologics Inc.), bacTRL-Spike (NCT04334980, Symvivo Corporation, Canada), INO-4800 (NCT04336410, Inovio Pharmaceuticals, USA), mRNA-1273 (NCT04283461, National Institute of Allergy and Infectious Diseases, USA), and SARS-CoV-2 rS (NCT04368988, Novavax). There are four vaccines on simultaneous Phase I-II: SARS-CoV-2 inactivated vaccine (NCT04352608, Sinovac Research and Development Co., Ltd.), LV-SMENP-DC (NCT04276896, Shenzhen Geno-Immune Medical Institute, China), ChAdOx1 (NCT04324606, University of Oxford, UK), and BNT162 (NCT04368728, Biontech SE, Pfizer). There is also one vaccine in Phase II: Ad5-nCoV (NCT04341389, Institute of Biotechnology, Academy of Military Medical Sciences, PLA of China) $(47,48)$. Of note, six peptidebased vaccines are currently under development: FlowVax ${ }^{\mathrm{TM}}$ by Flow Pharma Inc. (49), EPV-CoV19 by EpiVax (50), DPXCOVID-19 by IMV inc. (51), Vaxil Bio (US patent: 62/987,310) (52), OncoGen (53), and USask VIDO-InterVac (54). 
In this urgent race to develop a vaccine, immunoinformatic techniques represent a powerful approach that allows the screening of whole pathogen proteomes to identify potential immunogenic regions (55). This includes predicting linear epitopes potentially presented by the Human Leukocyte Antigen (HLA) class I and II, which can be used to design peptide vaccines (56) and molecular diagnostic tests (57). The state-of-the-art programs are based on artificial neural networks (58-61), and they require both the sequence of target protein(s) and the host HLA allele(s) at 4-digit resolution $(62,63)$.

Two recent studies have extrapolated epitopes with experimental evidence in SARS-CoV to SARS-CoV-2, and selected candidates based on different criteria. Grifoni et al. (64) intersected these extrapolated epitopes with a set of predicted epitopes using 12 HLA-I A and B supertypes (65). They present 12 candidates in the $\mathrm{S}, \mathrm{M}$, and $\mathrm{N}$ proteins of SARS-CoV-2. Ahmed et al. (66) subselected the extrapolated epitopes using the Population Tool of the Immune Epitope Database and Analysis Resource (IEDB) (67), resulting in candidates in the $\mathrm{S}$ and $\mathrm{N}$ proteins that may potentially cover the global population. This tool is based on the HLA frequencies reported in the Allele Frequency Net Database (AFNDB), which is an important reference source for immunological studies worldwide (68). Nevertheless, this database has little information about South America, missing large studies published in recent years comprising millions of people (see Table S3).

Lack of knowledge about the HLA allelic distribution in South America can cause regional misrepresentation in immunological studies, which could result in diminished efficiency of vaccines and diagnostic tests. Additionally, knowledge on HLA allelic frequencies typified at 4-digit resolution or higher also plays a determinant role in other areas, like transplantation (69), response to cancer immunotherapy (70), and susceptibility to autoimmune diseases $(71,72)$.

Here, we performed a literature review of HLA allele frequencies of South American populations reported in scientific articles available in PubMed and datasets available in the AFNDB. These datasets were integrated by country, calculating weighted allele frequencies (WAFs). Thus, we are presenting updated WAFs for most South American countries. Then, HLA class I and II epitopes were predicted using only alleles with $\mathrm{WAF} \geq 0.05$. Finally, we selected candidate epitopes covering all of these South American HLA alleles, reporting both candidates with existing experimental evidence in the IEDB database for other coronaviruses as well as novel candidates. These candidates complement those proposed in recent articles, which in most cases scarcely cover South America. Our findings may result in a better representation of South America, enriching current development efforts of vaccines and diagnostic tests.

\section{METHODS}

\section{Alignment, Entropy, and Selection Pressure of the SARS-CoV-2 Proteins}

A total of 2,123 genome sequences from human hosts, categorized as complete with high coverage in the Global
Initiative on Sharing All Influenza Data (GISAID) database (73), were downloaded on March 31, 2020. This comprises genomes from 55 countries, including 16 from Brazil, seven from Chile, and one from Peru (Tables S1, S2). These sequences were aligned in CLC Main Workbench v.20.0.3 (QIAGEN Bioinformatics). The coding regions corresponding to the viral proteins were extracted and translated, using as reference the sequences with GenBank Gene IDs: 43740568 (Spike, S), 43740571 (Membrane, M), 43740575 (Nucleocapside, N), 43740570 (Envelope, E), 43740569 (ORF3a), 43740572 (ORF6), 43740573 (ORF7a), 43740574 (ORF7b), 43740577 (ORF8), 43740576 (ORF10), and 43740578 (Orf1ab and NSP1-16 proteins).

Variability at each amino acid position of the SARS-CoV2 proteins was measured by Shannon Entropy (74), using the Shannon Entropy-One online tool (https://www.hiv.lanl. gov/content/sequence/ENTROPY/entropy_one.html). Sites with positive selection pressure were obtained from the SARS-CoV2 Natural Selection Analysis available in the Galaxy Project (https://covid19.galaxyproject.org/) (75), retrieved on May 3, 2020, considering the better-ranked sites (meeting at least four categories).

\section{South American HLA Alleles and Weighted Allele Frequencies (WAFs)}

A review was performed considering first only datasets available in the AFNDB containing allelic frequencies of HLA-A, -B, C, -DPA, -DPB, -DQA, -DQB, and -DRB1 in South American populations. This was called the "current scenario." We selected studies using the following inclusion criteria: (i) we collected all the studies characterizing HLA alleles with at least 4-digit resolution in 100 or more individuals ( $\mathrm{N} \geq 100$ ); and (ii) an auxiliary rule was exceptionally applied in low-information cases only, i.e., if just two or fewer articles were obtained, both barely passing the filter $(100 \leq \mathrm{N} \leq 200)$. This exception consisted of relaxing the lower cut-off to $\mathrm{N} \geq 40$, allowing smaller studies to pass the filter to rescue additional data.

To expand the "current scenario," in addition to the previously described datasets, we collected articles in PubMed reporting Class I and Class II HLA alleles of South American populations using the same inclusion criteria. This was called the "updated scenario." The selection criteria were applied to both published datasets in scientific articles and datasets available only in the AFNDB. All alleles were matched to the current HLA nomenclature (76).

Then, for both current and updated scenarios, we calculated Weighted Allele Frequencies (WAFs) by country, using as approximation the weighted average of the allele frequencies in all the studies selected by country. This led to a few exceptions due to evident discrepancies in technology and resolution, resulting in the exclusion of some studies (see Figure 1 and Supplementary Methods for full detail). Only alleles with $\mathrm{WAF} \geq 5 \%$ in the updated scenario were considered for further analysis.

\section{Epitope Prediction and Selection}

Linear epitopes for HLA class I (HLA-A, -B, and -C) and HLA class II (HLA-DRB1) were predicted in the SARS-CoV-2 proteins 


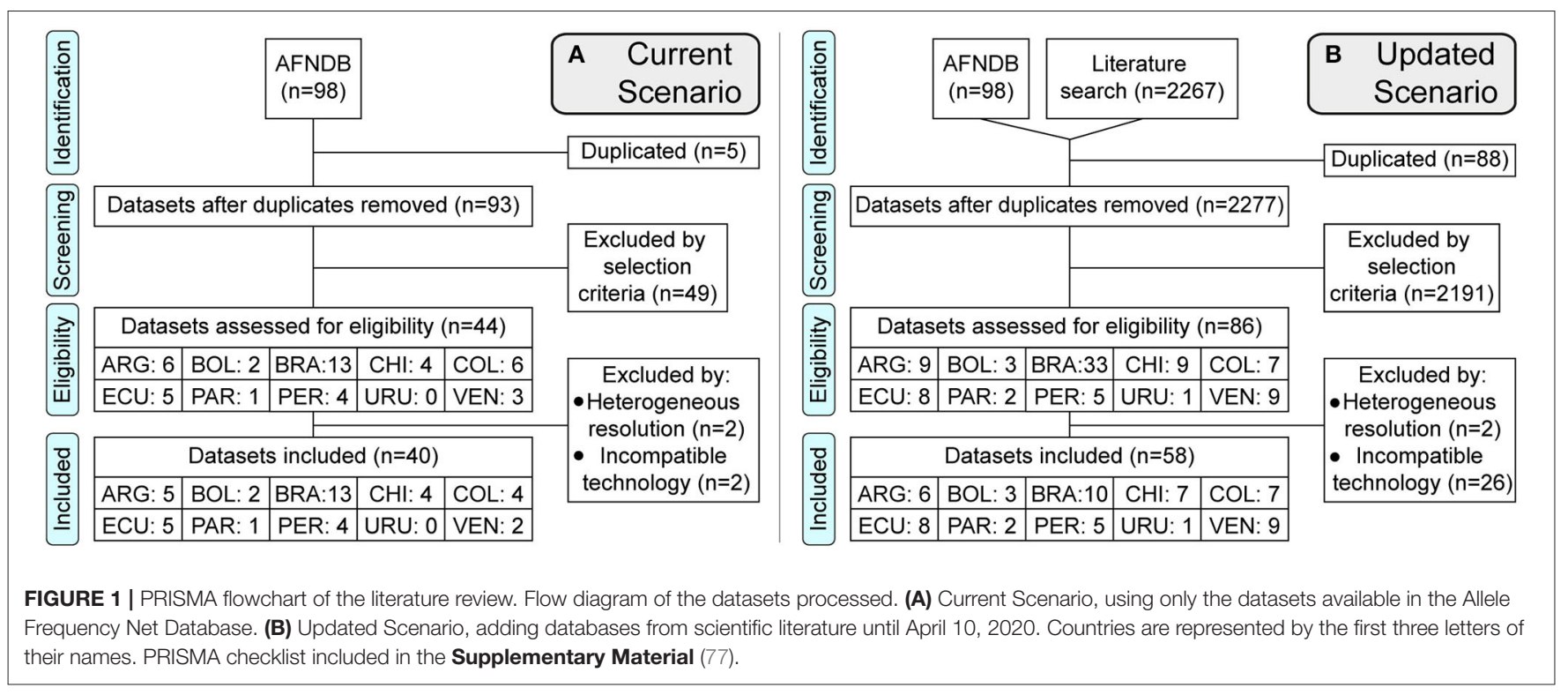

using the alleles obtained in the previous step and the cut-offs recommended by each software. For HLA class I, we predicted epitopes of 8-11aa using NetMHCpan v4.0 (59) with rank $\leq 2$ and MHCflurry v1.6.0 (60) with an affinity (IC50) $\leq 500 \mathrm{nM}$. As these programs do not have the same collection of HLA alleles available for prediction, we used the consensus verdict whenever possible. Otherwise, we only used the prediction of the software with the allele available. For HLA class II, we predicted epitopes of 15 aa using NetMHCIIpan v4.0 (61) with rank $\leq 10$. Then, we annotated which predicted epitopes have previous experimental evidence for other coronaviruses (identical match, either in full length from end to end or contained inside) in the IEDB Database (www.iedb.org) (67).

Each predicted epitope obtained corresponds to one or more HLA alleles, which have different WAFs by country. To combine these WAFs into a single value, we defined a Coverage Score (CS), which reflects how good a candidate epitope is for South America. This was calculated for each predicted epitope, by adding the proportion by country of alleles with WAF $\geq 5 \%$ that bind this predicted epitope. Therefore, this CS varies in a range from 0 to $P$, where $P$ is the number of countries. Then, we selected candidate epitopes with the highest Coverage Scores, with and without prior experimental evidence. Additionally, for HLA-II only, we prioritized candidates based on their three-dimensional exposure. Sequence logos were generated using WebLogo 3 (78), showing the chemistry and frequency per amino acid of our best candidates.

All the data was processed and analyzed using Python v3.8.2 (www.python.org) and R v3.6.3 (www.r-project.org) with Rstudio v1.2.5033 (www.rstudio.com).

\section{Prediction of Post-translational Modifications Events}

Signal peptide was predicted using Signal-3L 2.0 (79). Protein topology (inner, transmembrane, and outer regions) were predicted with MemBrain v3.1 (80). N-Glycosylation and OGlycosylation sites were predicted using N-Glycosite (81) and NetOGlyc v4 (82) (score $\geq 0.5$ ), respectively. Palmitoylation and Sumoylation sites were predicted using CSS-Palm 4.0 (83) (medium threshold, $\mathrm{Sn}=86.92 \%, \mathrm{Sp}=89.97 \%$ ) and GPS-SUMO v1.0 (84) (medium threshold, $\mathrm{Sn}=68.94 \%$, Sp $=95.01 \%$ ), respectively. Prediction of ADP-ribosylation sites was performed using ADPredict v1.1 (85) (score $\geq 0.4$ ). All predictions were manually curated based on Uniprot available annotations for SARS-CoV-2.

\section{Structural Modeling and Graphical Representation}

Candidate epitopes were mapped on the $3 \mathrm{D}$ structure of the $S$ protein. To avoid missing residues in the current crystal structure, we modeled the consensus sequence of the $S$ protein by homology using the SWISS-MODEL web server (86) (https:// swissmodel.expasy.org/), with the crystal structure as template (Protein Data Bank ID: 6VXX). Figures were generated in PyMOL v2.3.4 (https://pymol.org/2/) (87).

\section{RESULTS}

\section{Alignment, Entropy, and Selection Pressure of the SARS-CoV-2 Proteins}

Diversity at each amino acid position revealed high entropy values in the proteins NSP2 (T85I, score $=0.36$ ), NSP5 (L37F, score $=0.42)$, NSP12 (P323L, score $=0.69)$, NSP13 (P504L, score $=0.46$ and $Y 541 \mathrm{C}$, score $=0.47)$, Spike $(\mathrm{D} 614 \mathrm{G}$, score $=0.69)$, ORF3a (Q57H, score $=0.41$ and G251V, score $=0.31)$, ORF8 (L84S, score $=0.57)$, and Nucleocapsid $(\mathrm{R} 203 \mathrm{~K}$, score $=0.41$, and G204R, score $=0.41$ ).

Sites with the highest probability to be under positive selective pressure are located in NSP2 (T85, P568), NSP3 (K384, N444, P822, V1768, V1795), NSP6 (L75), NSP7 (S25), Spike (S943, 
G1124), ORF3a (A99, T14, L147), NSP12 (A97, L323, A449), NSP13 (V49), NSP14 (A482), and NSP16 (K160). See Figure 3 and Table S8.

\section{South American HLA Alleles and Weighted Allele Frequencies (WAFs)}

We found 44 eligible datasets for the "current scenario" and 86 for the "updated scenario", using only 40 and 58 to calculate the WAFs by country, respectively (Figure 1). The selection process is provided in full detail in the Supplementary Methods and Table S3.

The IEDB population coverage tool (http://tools.iedb.org/ population/) uses information provided by the AFNDB at 4-digit resolution, which in the case of South America comprises just a small number of populations: two from Argentina, one from Bolivia, five from Brazil, two from Chile, three from Colombia, two from Ecuador, one from Paraguay, two from Peru, and four from Venezuela. For the current scenario, we collected a similar number of datasets: five from Argentina, two from Bolivia, 13 from Brazil, four from Chile, four from Colombia, five from Ecuador, one from Paraguay, four from Peru, and two from Venezuela. In both cases, there was no data for Uruguay, Guyana, French Guiana, or Suriname.

Our literature review to update the allele frequencies included six datasets for Argentina, three for Bolivia, 10 for Brazil, seven for Chile, seven for Colombia, eight for Ecuador, two for Paraguay, five for Peru, one for Uruguay, and nine for Venezuela. In both scenarios (current and updated), we only obtained HLAII and not HLA-I data from Bolivia. All of the allele frequencies and sample sizes by study are provided in Table $\mathbf{S 4}$. The addition of new studies resulted in updated HLA allele frequencies.

We then calculated WAFs for each country (see Table S5). Some alleles with WAF under $5 \%$ in the current scenario are now above in the updated scenario: 13 alleles of Argentina, 15 of Brazil, seven of Chile, seven of Ecuador, one of Paraguay, two of Peru, and 19 of Venezuela. Additionally, some alleles not reported in the AFNDB for South America were found with WAF $\geq 5 \%$ in the updated scenario: six alleles of HLA-I C in Argentina, two HLA-II DQA1 in Ecuador, two HLA-I A and six HLA-I B in Paraguay, two HLA-I C in Peru, five HLA-II DQB1 in Uruguay, and four HLA-II DPA1 in Venezuela (see Figure 2). Details provided in Table $\mathbf{S 6}$.

\section{Epitope Prediction}

We obtained 11,644 predicted T cell epitopes in SARS-CoV2 proteins: 7,517 for HLA-I and 4,127 for HLA-II. We found that 1400 have previous experimental evidence in the IEDB: 25 in positive T cell assays, 1327 in positive MHC-ligand binding assays, and 48 in both (see Table S7).

In the $\mathrm{S}$ protein, we predicted 961 HLA-I epitopes. Previous experimental evidence was found for 113, although they had low CS (0.048-2.146). The best two predicted epitopes with the highest CS (VVFLHVTYV, CS $=2.146$, IEDB-ID: 71663 and LQIPFAMQM, CS $=2.043$, IEDB-ID: 38855) cover almost one allele with WAF $\geq 5 \%$ by country. These were previously proposed as candidates by Ahmed et al., 2020 (66). Other predicted epitopes already proposed as candidates in similar studies $(64,66)$ have lower CS. From the 848 predicted epitopes without experimental evidence, the top three with the highest CS cover at least one allele with WAF $\geq$ $5 \%$ by country. These represent novel candidates (Table 1): MIAQYTSAL (CS $=4.127)$, SIIAYTMSL $(C S=3.739)$, and YLQPRTFLL $(\mathrm{CS}=3.646)$.

We predicted 6556 HLA-I epitopes in other SARS-CoV-2 proteins. Experimental evidence was reported for 1122, and the 10 with the highest CS (2.520-3.346) cover at least one allele with $\mathrm{WAF} \geq 5 \%$ by country. These predicted epitopes are located in the ORF6 and NSP proteins, and represent novel candidates. The highest CS (3.346) corresponds to YADVFHLYL, located in the NSP12 protein. We also found 5434 predicted epitopes without experimental evidence. The top seven with the highest CS (3.1484.013) are novel candidates, located in NSP proteins, and cover at least one allele with $\mathrm{WAF} \geq 5 \%$ by country. The candidate with the highest CS (FAQDGNAAI, 4.013) is also located in the NSP12 protein (see Table 1).

For HLA-II, we predicted 628 epitopes in the S protein. Twenty-eight have experimental evidence, and the two with the highest CS (RAAEIRASANLAATK, CS $=9.000$, IEDB-ID: 100428 and IRAAEIRASANLAAT, CS $=8.148$, IEDB-ID: 100428) are contiguous and belong to the $\mathrm{CH}$ region. They represent novel candidates (see Table 2). The next two, LDKYFKNHTSPDVDL (CS $=6.760$, IEDB-ID: 35205$)$ and DKYFKNHTSPDVDLG (CS $=6.760$, IEDB-ID: 9006), are also contiguous and correspond to the HR2 region (Figure 3D). These two were selected as candidates in a previous study (66).

We also predicted 601 epitopes without experimental evidence in the S protein, where 41 had $6.017 \leq \mathrm{CS} \leq 9.000$ (Figure 3D). Some of these are located in notoriously exposed regions (see Figure 4). All of these are novel candidates, including EKGIYQTSNFRVQPT (CS = 8.490), QTSNFRVQPTESIVR (CS $=8.714)$, and TSNFRVQPTESIVRF (CS $=9.000$, the maximum possible score), which overlap in the RBD and have a remarkably high CS.

We obtained 81 HLA-II predicted epitopes in the M protein. Only one (PKEITVATSRTLSYY, CS $=6.110$ ) has a reported experiment (IEDB-ID: 48051), an MHC-ligand assay presenting the peptide to the HLA-DRB1*01:01, measuring the affinity. It was already selected as a candidate in another study (66). Nevertheless, it is located in a predicted intra-virion region. Of those without experimental evidence and located outside the virion, TITVEELKKLLEQWN has the best CS (3.326) (see Figure 3F). In the E protein, we predicted 15 HLAII epitopes. Similarly, only LVTLAILTALRLCAY has previous experimental evidence, but a very low CS (0.143), and it is located in a predicted non-external region. However, the candidate MYSFVSEETGTLIVN (CS $=1.764)$ is located outside the virion (Figure 3H). Sequence logos of our class-I and class-II candidate epitopes are presented in Figures S1, S2, respectively.

To cover all the HLA alleles with WAF $\geq 5 \%$ in South America, we included five additional candidates. We selected predicted epitopes that bind to HLA alleles not covered by any of the candidates already selected, choosing those with the highest CS. Two have experimental evidence: MPASWVMRI (in NSP6, CS: 2.292, IEDB ID: 42260 and 


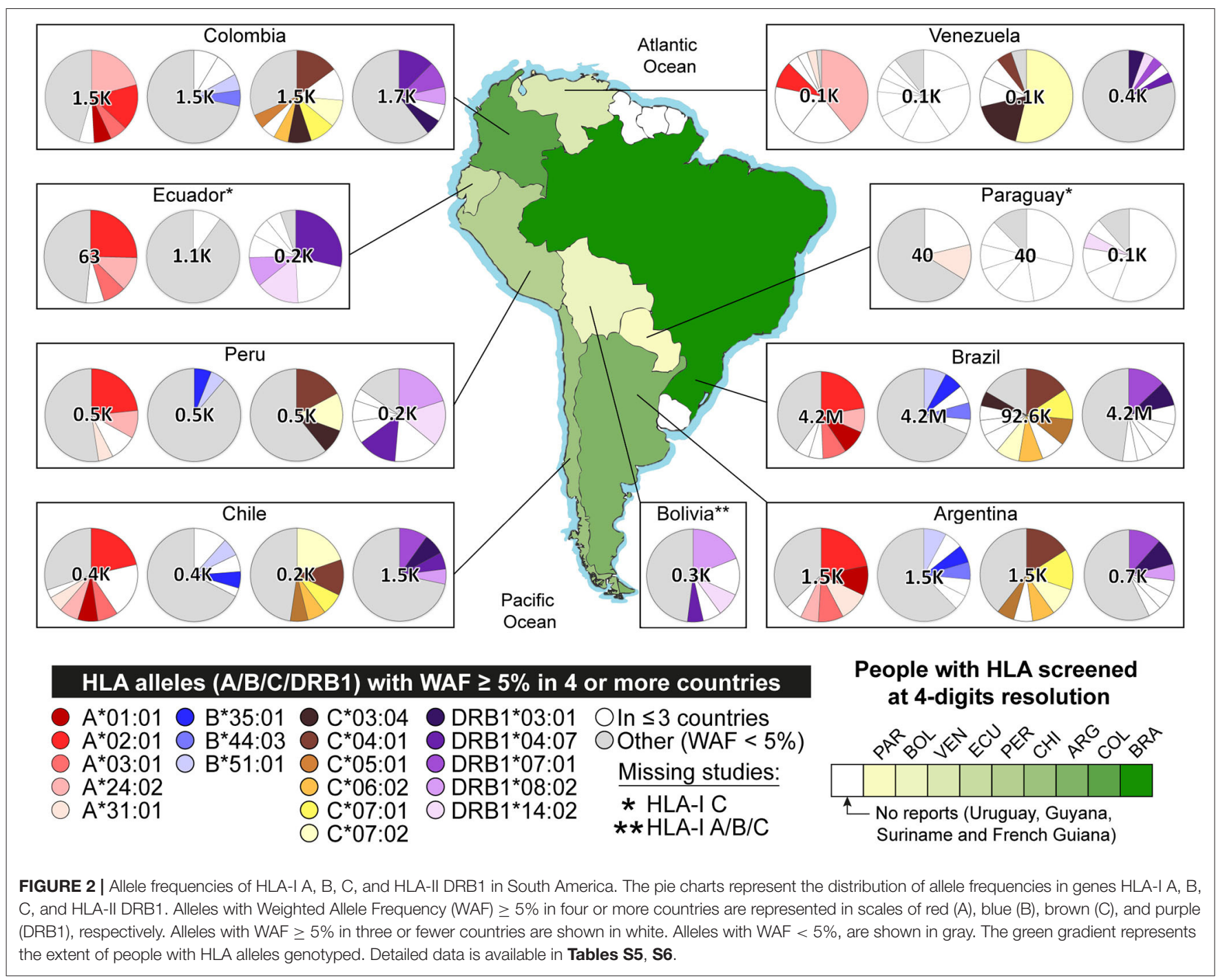

42261) and SEFDRDAAM (in NSP12, CS:1.832, IEDB ID: 57419). The remaining three have no experimental evidence: GEYSHVVAF (in NSP4, CS: 2.270), KLFDRYFKY (in NSP12, CS: 2.169) and GLNDNLLEI (in NSP2, CS: 1.705).

\section{Prediction of Post-translational Modifications Events}

Twenty two potential N-linked glycosylation sites were predicted along the $\mathrm{S}$ protein in three clusters: (i) inside the NTD and RBD regions (N17, N61, N74, N122, N149, N165, N234, $\mathrm{N} 282, \mathrm{~N} 331$, and N343); (ii) in the proximity of the S1/S2 and S2' cleavage sites (N603, N616, N657, N709, N717, and N801); and (iii) near the C-terminus (N1074, N1098, N1134, N1158, N1173, and N1194). In the M protein, one predicted $\mathrm{N}$-linked glycosylation site $(\mathrm{N} 5)$ is located in the exposed region, and it has been associated with antigenicity and transport in some coronaviruses (88). The E protein presents two potential N-linked glycosylation sites: N48, probably non-functional (89), and N66, suggested in SARS$\mathrm{CoV}$ to be potentially associated with monomeric forms (90). ORF8 also presents a potential N-linked glycosylation site in N78, which could stabilize and protect the protein from proteasomal degradation, as occurring in SARS-CoV (91). Olinked glycosylations were predicted in residues S673, T678, and S686 of the S protein and residues T32 and T34 of the ORF3a. These events were experimentally detected in SARS-CoV (92). However, glycosylation in residues 686 (O-linked) and 1158 (N-linked) were not confirmed by mass spectrometry in a recent study (93).

Then, the predicted glycosylation sites were contrasted with the best HLA-II candidate epitopes for South America (Table 2). Sites N61, N122, N801, N1074, N1098, and N1158 are located in nine HLA-II candidate epitopes. Additionally, sites N234, N331, N709, and the O-linked 686 fall near eight candidate epitopes.

Predicted palmitoylation sites fall into the cytoplasmic tail (C1235, C1236, C1240, C1243, C1247, C1248, C1250, 
TABLE 1 | Best HLA-I candidate epitopes for South America in SARS-CoV-2 proteins.

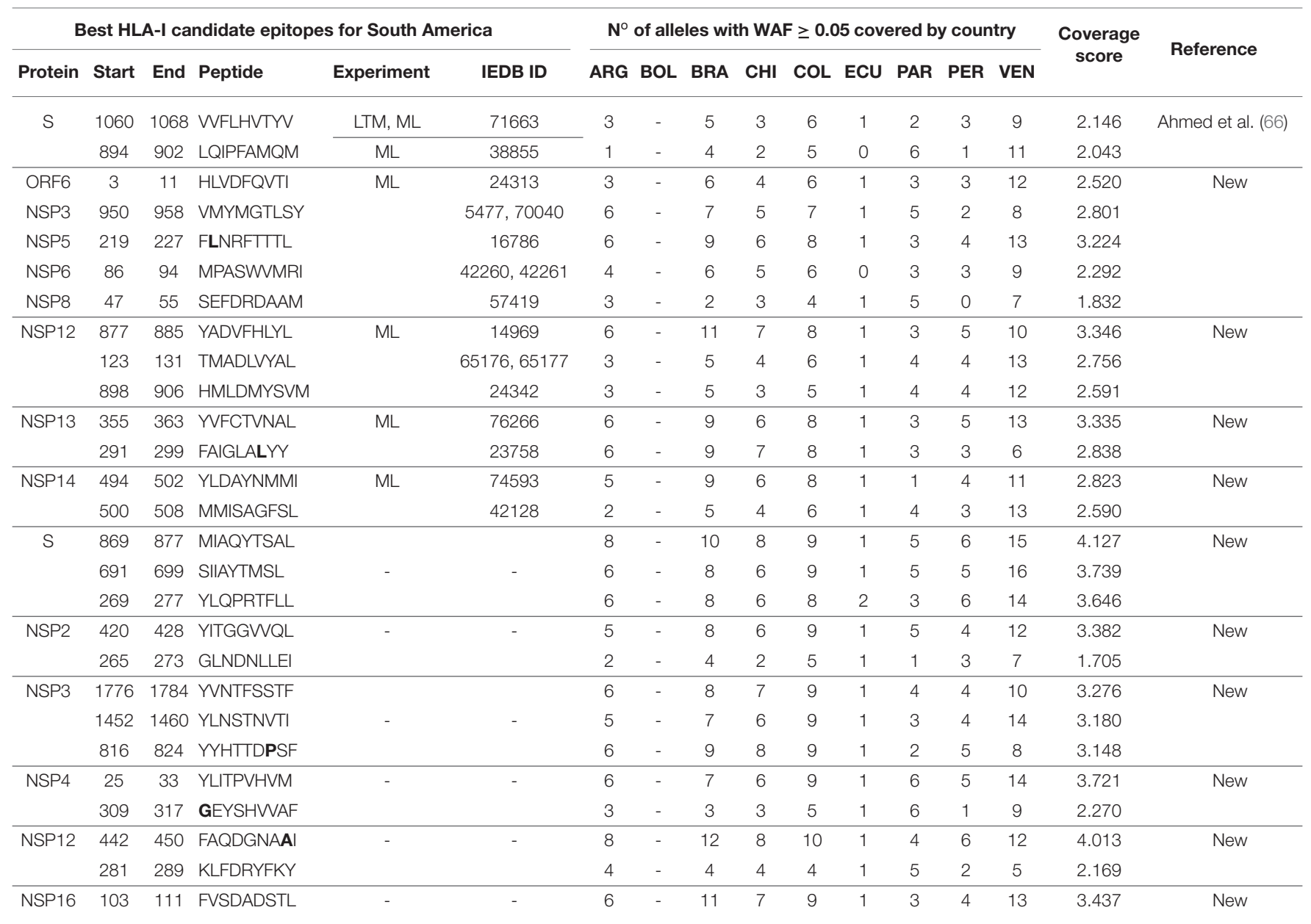

These candidate epitopes were selected from our prediction based on their scores (rank for NetMHC and IC50 for MHCflurry) and Coverage Score (CS). Experimental evidence including the IEDB ID and experiment type (LTM: linearT_MHC, ML: MHC_ligand) is provided when available. Scientific articles already proposing these candidates are mentioned. Residues in bold represent positive selection pressure sites.

C1253, and C1254) of the S protein and three cysteines (C40, C43, and C44) of the E protein. These sites have been previously reported in SARS-CoV (94), being associated with protein subcellular trafficking, stability and viral assembly $(95,96)$.

In the $\mathrm{N}$ protein, a potential sumoylation site was predicted in K338. Li et al. (97) explored sumoylation events experimentally in SARS-CoV, not finding K338 but detecting the site K62. This site was also detected in our prediction using a less restrictive threshold. This corresponds to K61 in SARS-CoV-2, having an Asp instead of Glu in the canonical consensus motif. This site has been associated with self homo-oligomerization and host cell division interference.

ADP-ribosylation prediction identified eight potential sites along the nucleocapsid (D22, E118, E136, E231, E253, E323, E378, and D415). This PTM was also reported in other coronaviruses, and can be related to the virus infective phase (33) (see Figure 3 and Table S8).

\section{Structural Modeling of the S Protein}

The monomer model generated is composed of the first 1147 residues of the SARS-CoV-2 Spike protein. It fills the gaps of the crystal structure PDB:6VXX at positions 1-26, 70-79, 144164, 173-185, 246-262, 445-446, 455-461, 469-488, 502, 621-640, 677-688, and 828-853.

HLA-II candidate epitopes shown in Figure 3 were mapped to the trimeric $3 \mathrm{D}$-structure in order to visualize their exposure (Figure 4). However, residues 1148-1273 were not represented in our model as they are missing in the reference crystal (22). Candidates in this missing region are represented in Figure 3D only.

\section{DISCUSSION}

There is an urgent need to develop vaccines and better diagnostic tests for COVID-19, targeting specific immunogenic regions and epitopes with protective potential and population 
TABLE 2 | Best HLA-II candidate epitopes for South America in SARS-CoV-2 proteins.

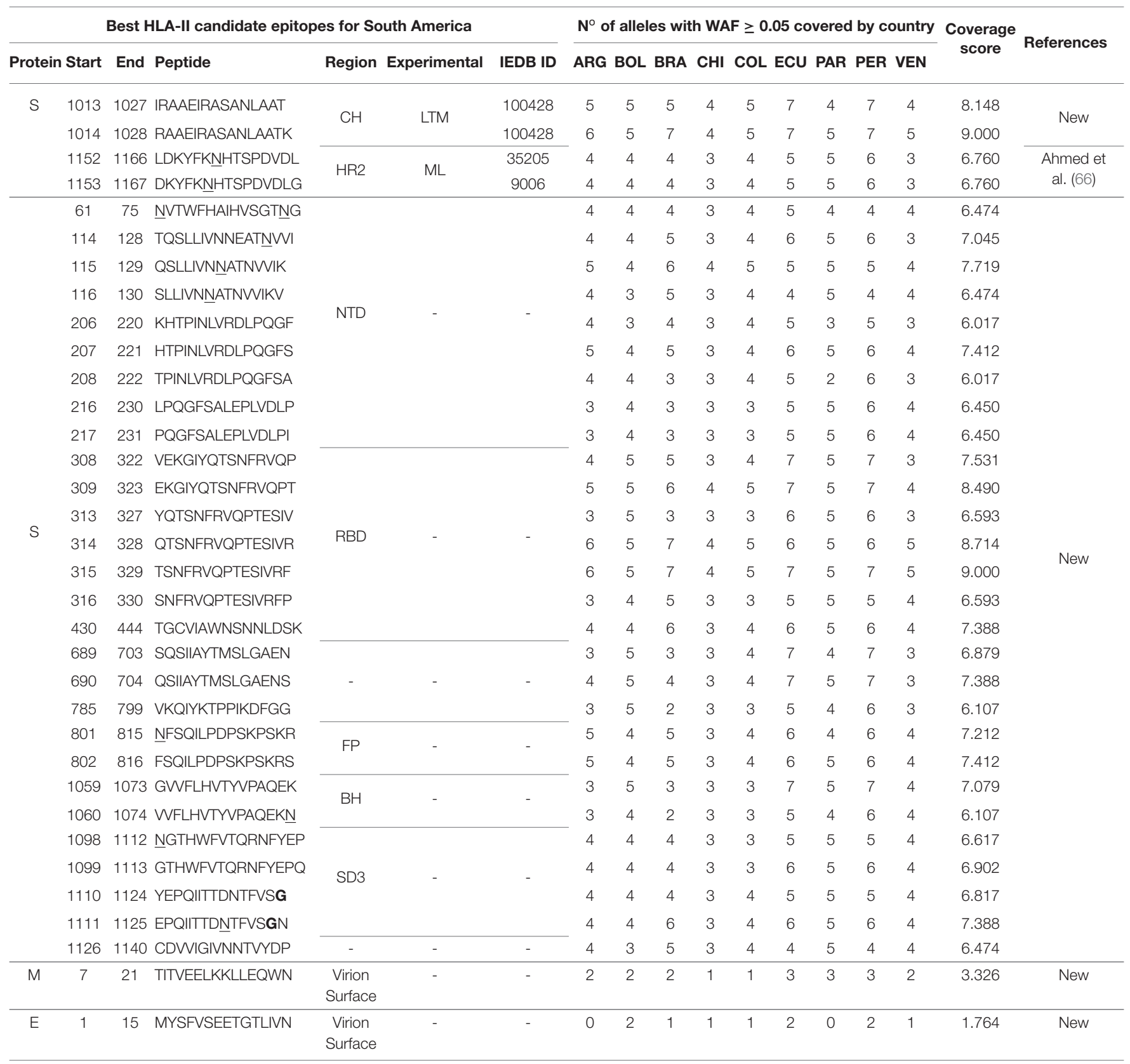

These candidate epitopes were selected from our prediction based on their scores (rank for NetMHC and IC50 for MHCflurry), Coverage Score (CS), and exposure (for Class-II only). Experimental evidence including the IEDB ID and experiment type (LTM: linearT_MHC, ML: MHC_ligand) is provided when available. Scientific articles already proposing these candidates are mentioned. Underlined residues indicate sites with predicted $\mathrm{N}$-linked glycosylations. Residues in bold represent positive selection pressure sites.

representativeness. Our research presents an updated report of HLA genotypes of South American populations, which led to a selection of candidate epitopes for HLA class I and II supported by experimental evidence as well as novel candidates, predicted to cover all South American countries.

The AFNDB and the IEDB population coverage tools are frequently used by the scientific community worldwide as reference sources of HLA frequencies (68), meaning it is crucial to have them updated. However, their collection and curation of new data rely on the scientific community users $(68,98)$. For
South America, these databases contain mostly small datasets coming from ethnic groups, not representative of the countries' diversity, resulting in a current inaccurate distribution of HLA frequencies (see Table S6). We have found 30 large datasets from 10 South American countries which were not included in the AFNDB. Our literature review represents a large update from a scenario of 20,124 to now $12,857,200$ datapoints among all the alleles collected of HLA-A, -B, -C, -DPA1, -DPB1, -DQA1, -DQB1, and -DRB1. This is reflected in 86 HLA alleles with $\mathrm{WAF} \geq 5 \%$ in the updated scenario, which were previously 


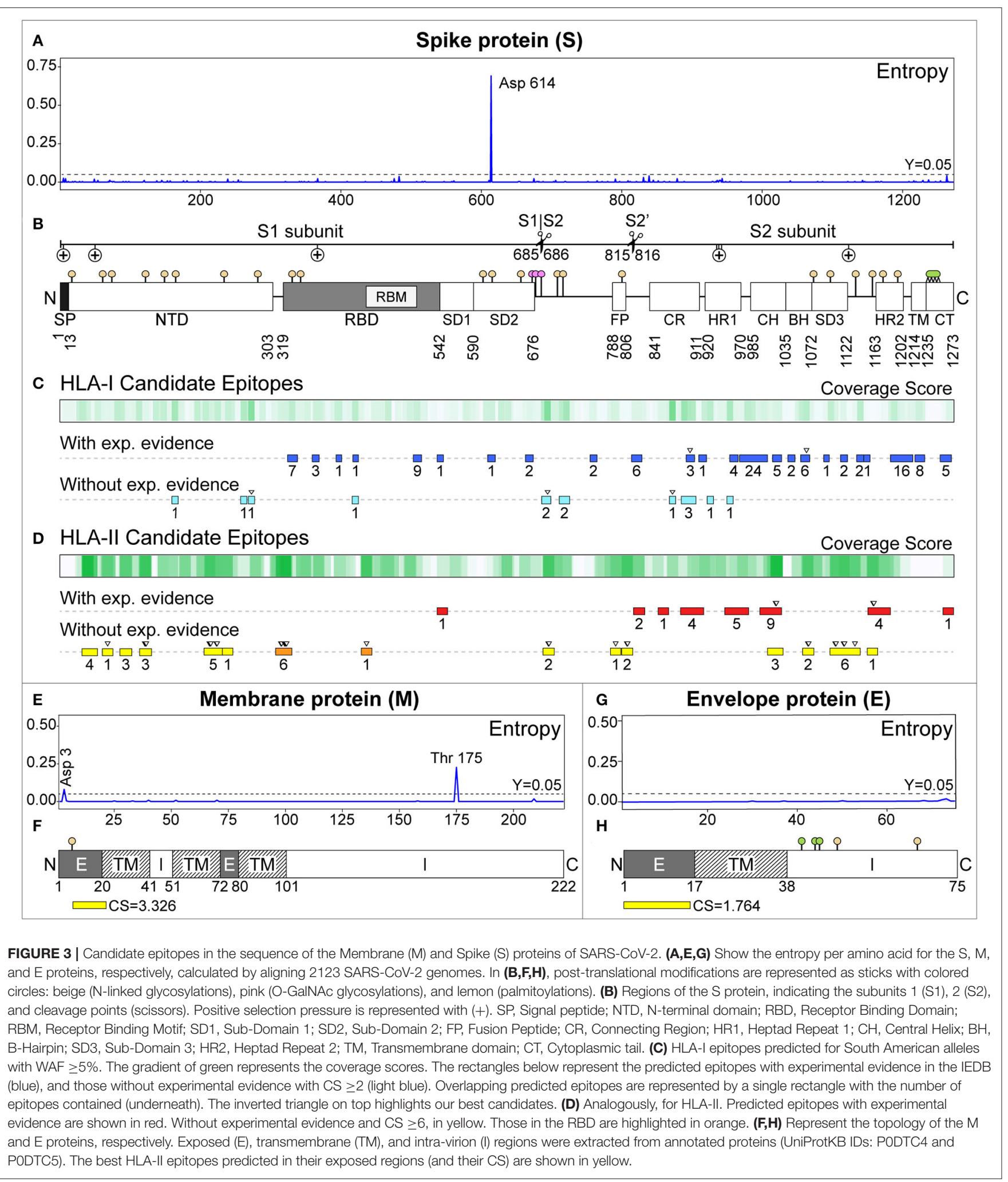

considered with frequencies under $5 \%$ or missing in the current scenario. This issue results in a misrepresentation of South America that could be affecting multiple immunological studies using these sources, like Ahmed et al. (66) and other SARS-CoV2 recent studies in the pre-print stage. To encourage and facilitate using the information collected, we are providing the datasets 
A

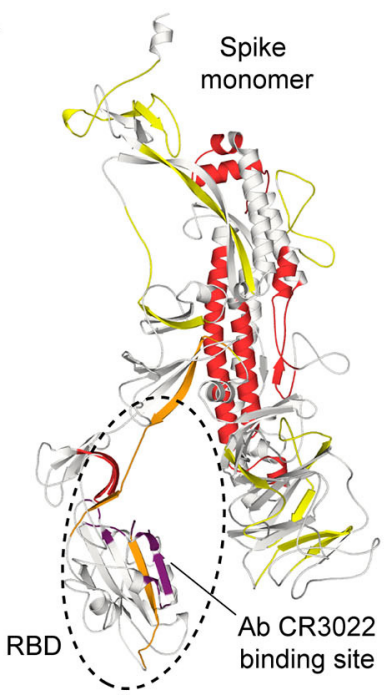

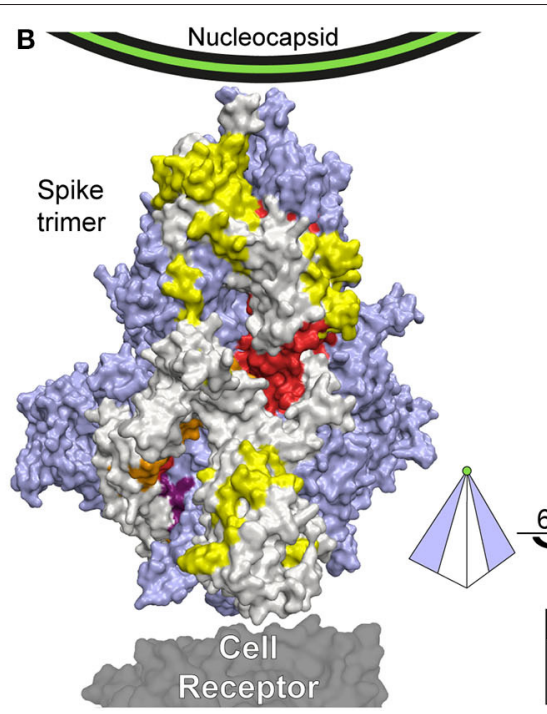

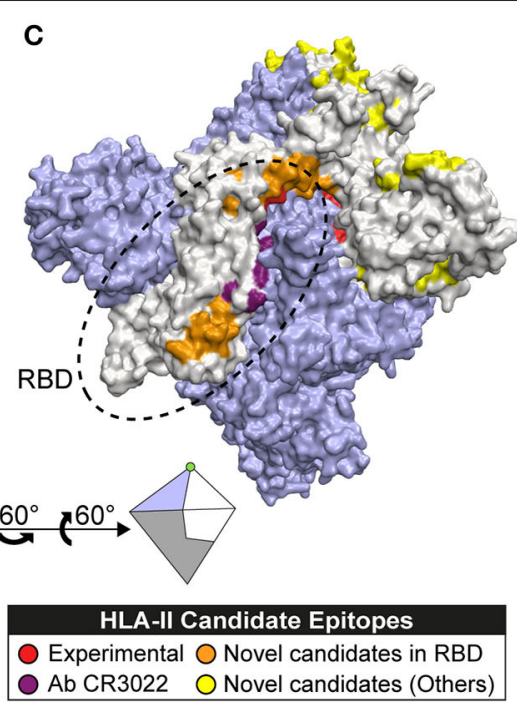

FIGURE 4 | Candidate epitopes in the 3D structure of the Spike (S) protein of SARS-CoV-2. This figure shows our HLA-II candidate epitopes with experimental evidence (red), without experimental evidence and CS $\geq 6$ (orange: located in RBD, yellow: located in other regions), and the binding site of the Ab CR3022 (violet). Candidate epitopes were mapped to the Spike monomer (A), and the Spike trimer (B and $\mathbf{C})$. The monomer is represented in beige, and the other 2 subunits in light purple. (C) Rotation of the trimer showing the RBD region. A pyramid representing the trimer is shown as visual aid to represent the rotation.

by country in their full extent (Tables S3, S4) and averaged (Tables S5, S6), as well as the selection and matching process in full detail (Supplementary Methods).

We are also presenting weighted allele frequencies by country, providing a one-sight representation of South America HLA abundances (Figure 2). This clearly shows that some HLA genes are understudied, especially in countries like Venezuela, Bolivia, and Paraguay. Moreover, there is no data from Uruguay, Guyana, French Guiana, or Suriname (68). We recommend genotyping the HLA of large populations to reduce diversity misrepresentation, like the study of the Brazilian bone marrow registry (99), which provided HLA alleles of millions of people.

Epitopes were predicted using MHCflurry v1.6.0 (60), NetMHCpan v4.0 (59), and NetMHCIIpan v4.0 (61). These state-of-the-art software are based on neural networks and use binding, stability, and eluted MHC-ligand mass spectrometry data (58). The recent update of NetMHCIIpan from v3.2 to v4.0 represents an evident improvement in prediction accuracy, being necessary to use the last version. We enriched our predictions, adding the experimental evidence reported in the IEDB for other coronaviruses. Nevertheless, certain class-II potential epitopes found in binding experiments (i.e., measuring the affinity of epitopes presented in-vitro to the MHC molecule) were located in transmembrane or internal regions. As the conformational dynamics of SARS-CoV-2 proteins remains unknown, we opted for being extra cautious, selecting only class-II candidate epitopes in known exposed regions of the protein structure.

We then define a Coverage Score (CS), a metric representing to what extent a candidate epitope covers the HLA alleles of South America. As this score is based on alleles and not on haplotypes, it might be overestimating the actual coverage. However, it represents a reasonable approximation for the current available data, mostly reported as allelic frequencies.
Based on the CS, we are presenting the best predicted epitopes, with and without experimental evidence, as potential candidates. Remarkably, we found novel candidates with very high CS, some located in immunologically relevant regions like the RBD of the Spike protein. And exposed regions of the $\mathrm{M}$ and $\mathrm{E}$ proteins (Figures 3, 4).

Viral clearance of SARS-CoV-2 infection requires activating subsets of $\mathrm{CD}^{+}$and $\mathrm{CD}^{+}{ }^{+} \mathrm{T}$ cells (100). Whereas, HLA-I epitopes are derived from both structural and non-structural proteins due to their endogenous processing, HLA-II epitopes have exogenous processing, being structural proteins (like $S, M$, or E) of particular interest (64). In SARS-CoV, $\mathrm{CD}^{+} \mathrm{T}$ cell response was previously shown to be greater than $\mathrm{CD}^{+}$, and it is widely elicited by different proteins including the replicase (ORF1ab) and NSPs (101). Even though structural proteins are associated with stronger T-cell responses (102-104), nonstructural proteins can also induce an immune response and provide additional epitopes (101). Similar experimental studies are needed to corroborate the same behavior in SARS-CoV-2. In fact, we found several HLA-I candidate epitopes in NSP proteins with a high coverage of South American HLA alleles, with and without experimental evidence (Table 1).

Several studies had demonstrated the immunogenicity of protein $\mathrm{S}$ in beta-coronaviruses, being the main target for vaccine development (22, 105-109). Its receptor binding domain (RBD) interacts with the human receptor ACE2, playing a crucial role during the viral entry process (110). Therefore, antibodies binding this region could potentially impede viral recognition. We are presenting 32 HLA-II candidate epitopes in the S protein, including seven novel candidates located in the RBD and exposed in the 3D structure. This includes the candidate epitope TSNFRVQPTESIVRF, which covers all the HLA-II alleles of South America. Some of our candidates are located near the 
binding site of the monoclonal antibody CR3022 in the RBD $(111,112)$ (Figure 4C). This antibody neutralizes SARS-CoV (113), opening the possibility of finding neutralizing antibodies against our HLA-II candidate epitopes. Additionally, neutralizing monoclonal antibodies has been generated against S1 and S2 for SARS $(104,114)$, and against the RBD for SARS $(115,116)$ and MERS $(117,118)$.

Other domains of the $S$ protein with predicted HLA-II epitopes are in accordance with previous evidence in other coronaviruses. It has been shown that the fusion peptide, the HR1 region, and the central helix are potential targets for broadly neutralizing antibodies (119). We also found candidate epitopes located in exposed regions of the NTD, the Subdomain 3 (SD3), the B-hairpin (BH), the Central Helix (CH), the Heptad Repeat (HR2), and linker regions, which could serve as potential antibody targets. Peptides derived from the Heptad regions HR1 and HR2 have proven to be effective inhibitors of viral fusion in SARS $(120,121)$ and MERS $(122,123)$. Moreover, conformational changes of the $S$ protein trimer could explain the presence of cryptic class-II epitopes (not accessible in the canonical 3D structure) (112). This opens up the possibility of finding candidate epitopes in unexposed regions of the protein, as hinted by our predicted epitopes with experimental MHCpeptide binding evidence (Figure 4B).

Our HLA-I and HLA-II candidate epitopes cover $100 \%$ of the alleles with WAF $\geq 5 \%$ in South America. Remarkably, we obtained two HLA-II candidate epitopes with the maximum CS possible (covering all the alleles), one with experimental evidence.

Some of our predicted epitopes have been previously reported by other studies using similar approaches (Tables 1, 2). Our selection agrees with two candidate epitopes from Ahmed et al. (66). They collected experimentally-determined epitopes and the corresponding alleles against which these were tested. Then, they used the IEDB population coverage tool to select 87 candidate epitopes for one HLA-II and 32 HLA-I alleles in total, aiming to cover $96.29 \%$ of people worldwide. These alleles represent only $18 / 47(38.3 \%)$ of the HLA-I and 1/18 (5.6\%) of the HLA-II alleles with $\mathrm{WAF} \geq 5 \%$ in our literature review for South America. Moreover, using the same tool with their candidates and alleles, but selecting South American populations only (according to the tool), we obtained a coverage of just $90.6 \%$ HLA-I and 4.1\% HLA-II alleles. These comparisons were done using only the experimentally-determined binding alleles. Furthermore, we explored if their candidate epitopes could bind our alleles using our prediction methodology (i.e., calculating the affinity of their candidate epitopes to the South American HLA alleles with $\mathrm{WAF} \geq 5 \%$ ). However, we obtained a match of just $43 / 47$ (91.49\%, HLA-I) and 11/18 (61.11\%, HLA-II). Altogether, this suggests a misrepresentation that leads to diminished coverage for South America.

Grifoni et al. (64) selected candidate epitopes in SARS-CoV-2 through: (i) sequence homology with epitopes with experimental evidence in SARS-CoV, and by (ii) epitope prediction, using 12 supertype representatives (the six most frequent HLA-I A and B alleles worldwide). Intersecting these two sources, they selected 12 HLA-I candidate epitopes in common, having an identity $\geq$ $90 \%$ with SARS-CoV. Their selection does not agree with any of our candidates. However, during their prediction, they obtained 12 HLA-I (CS: 0.095-3.739) and two HLA-II (CS: 6.474-6.593) predicted epitopes that have better scores for South America and match with some of our candidates. Nevertheless, further steps in their selection criteria made them drop these candidates. This is attributable to their strict filtering, due to the fact that they relied on experimental evidence from SARS-CoV only, as well as the small number of supertype alleles and epitopes chosen.

An important improvement in selecting the best candidate epitopes is to consider problematic sites affected by entropy, selective pressure, post-translational modifications, and other effects. Some of these considerations have been demonstrated to assist in developing molecular diagnosis in coronaviruses and other species $(124,125)$. Amino acid variants can result in diverse changes affecting the infectious and adaptive virus behavior. Entropy analysis revealed highly variable sites such as P323L in NSP12 (RdRp) or D614G in the S protein. Further biological consequences could be obtained from the sites affected by positive selective pressures, like T85 in NSP2, S25 in NSP7, and A99 in ORF3a. In the present study, we found that five of 27 HLAI and two of 34 HLA-II candidate epitopes contain predicted sites affected by positive selective pressure (shown in bold in Tables $\mathbf{1}$, 2). However, we decided to keep these epitopes in our list of potential candidates due to their high CS and low amino acid variability (under 5\%) in the current pandemic wave.

We predicted PTMs, including glycosylation, palmitoylation, sumoylation, and ADP-ribosylation events, in order to find relevant sites for the viral cycle. Sites affected by these events are expected to be conserved as they fulfill critical functions in viruses $(33,95-97)$. N-linked glycosylation is one of the most frequents PTMs with potential effects over the folding, tropism, interactions with host proteases, antibody recognition, and antigenicity of the Spike protein (126-131). $\mathrm{N}$-linked glycosylations have been predicted in our candidate epitopes, including those with experimental evidence (Table S8). SARS-CoV-2 Spike protein possesses 22 potential N-linked glycosylation sites (Figure 3), mainly distributed in S1 and the C-terminal region of the S2 $(119,132)$. Some of them are located in the NTD and near the S1/S2 cleavage region (N122, N165, N234, N603, and N717). These sites surround the ACE2binding domain and were shown to be critical for viral entry mediated by DC-SIGN (dendritic cell-specific ICAM-3-grabbing non-integrin) and L-SIGN (liver/lymph node-specific ICAM-3grabbing non-integrin) (133), which are two C-type lectins that recognize high-mannose glycans (134). In contrast to SARSCoV, SARS-CoV-2 presents an additional site (N657, near the S2 cleavage) and misses the glycosylation site N370 (in the $\mathrm{RBD}$ region), due to the absence of Ser/Thr to complete the sequon. Although this does not alter the affinity to the ACE2 receptor (135), it can significantly reduce DC-SIGN binding capacity (136). Thus, availability of N-linked glycosylations sites and differential affinities to ACE2, DC-SIGN, or L-SIGN may act as either enhancer forces or alternative mechanisms for viral entry $(23,137)$. Additionally, sites N227 and N699 in SARSCoV (equivalent to N234 and N717 in SARS-CoV-2) have been hypothesized to facilitate the zoonotic transmission of this virus (133). A recent study based on liquid-chromatography-mass 
spectrometry (LC-MS) (132) confirmed the occurrence of $\mathrm{N}$ linked glycosylation in all of our predicted sites. However, another study using LC-MS/MS (93) found only 17 out of 22 of the predicted sites. These differences could be due to the different experimental design and procedures used. Moreover, the composition diversity (oligomannose, complex, or hybridtype), and frequency of these glycosylation events were dissimilar in both studies.

O-linked glycosylations were predicted at three previously proposed sites flanking the S1/S2 cleavage site (138). These events were not found in two recent mass spectrometry studies $(93,132)$. Thus, occurrence of these events could be very rare or affected by intra-host conditions. Interestingly, T323 and S325 in RBD were detected as O-glycosylated (93), which may be related to increasing affinity with the human receptor ACE2 $(110,139)$. Nand O-linked glycosylation events can influence not only their position but also the surrounding area under the glycan shield. In fact, both $\mathrm{N}$ - and O-linked glycosylations could be associated with masking epitopes or important amino acids, resulting in immune evasion $(129,140,141)$. Further in-vivo studies should be performed to determine the real complexity and heterogeneity of these events.

Meanwhile, palmitoylation predicted sites in the cytoplasmic tail of the S protein (Table S8) have been reported in other Coronaviruses (34). The presence of these sites supports the importance of membrane-proximal cysteine-rich clusters in processes like the Spike-mediated cell fusion (27, 95, 142), infectivity (143), and viral assembly $(144,145)$.

Conservation of PTMs in amino acids can support the selection of candidate epitopes. In contrast, their emergence or disappearance resulting in better fitness should be considered important evolutive events and must be particularly monitored. In sum, the emergence/disappearance of alternative codons affecting PTMs in the evolutive course of the current pandemic is intriguing, and it has already been noticed in some SARS-CoV-2 genomes (73). Additional studies may unravel the impact of these events and could help in the development of strategies to control the infectious viral cycle.

In summary, our study provides updated HLA allele frequencies for South America, rectifying previously misrepresented alleles. This led to the identification of potential Class-I and -II epitopes in SARS-CoV-2 with high regional coverage. Some are supported by existing experimental evidence, while the rest represent novel candidates. These could represent targets for neutralizing antibodies or could be used for the development of vaccines and diagnostics tests, which needs to be further studied. Our study highlights the advantage of a regionally-focused design. Approaches based on the global population have the advantage of broad coverage. However, this may result in leaving aside the best regional candidates and reducing the regional population coverage, as shown in this study. Furthermore, incorrect HLA frequencies could result in misleading results and misrepresentation of certain populations. We hope our findings may promote regional efforts with potentially better specificity.

Additionally, the exuberant immune response against SARSCoV-2 infections is related to disease severity $(146,147)$.
COVID-19 has shown cases of minimal manifestations in people within the risk group as well as fatal response in people without apparent risk, thereby suggesting a genetic predisposition (148). In that sense, information about the HLA allele frequencies distribution in different populations may contribute to study the magnitude of the immune response and its severity.

Lack of knowledge of the HLA allele frequencies' distribution in South America also limits regional scientific studies in the field. This impacts the study of infectious and autoimmune diseases, cancer immunotherapy, and transplantations. Our results will serve as an immediate source of information for multiple ongoing studies based on HLA allele frequencies.

In conclusion, the candidate epitopes presented may help in the fight against SARS-CoV-2, providing valuable information for the development of peptide vaccines and diagnostic tests. And updated HLA allele frequencies will impact on the study of many human diseases. We hope this literature review may result in a better representation of South America in future immunogenetic studies.

\section{DATA AVAILABILITY STATEMENT}

All datasets generated for this study are included in the article/Supplementary Material.

\section{AUTHOR CONTRIBUTIONS}

$\mathrm{DR}$ and RC devised the research project. DR, AM, and OM-S performed the literature review. DR, MR, and RC selected and analyzed the viral genomes. DR, AM, and MR performed the epitope predictions. DR, AM, MR, and OM$S$ matched the predicted epitopes with previous experimental data and published predictions. AM and MR modeled the protein structures. AM, DR, and RC performed the prediction of selection pressures and post-translational modifications. AM and DR prepared the figures. All authors contributed to analyzing the results and manuscript preparation.

\section{FUNDING}

The publication fee of this study was sponsored by the Vicerectorate for Research and Postgraduate Studies of the National University of San Marcos (Vicerrectorado de Investigación y Posgrado de la Universidad Nacional Mayor de San Marcos).

\section{ACKNOWLEDGMENTS}

We gratefully acknowledge the authors and laboratories that generated and submitted genome sequences to the GISAID's EpiCov $^{\mathrm{TM}}$ Database, on which this research is based. The detailed list of genomes sequenced used, authors, and submitting laboratories is provided in Table S1. All submitters of data may be contacted directly via www.gisaid.org. We also thank Rydberg Supo-Escalante and Eduardo Gushiken for their critical observations and recommendations during the course of this research. 
Finally, we warmly thank the Professional School of Genetics and Biotechnology at the National University of San Marcos (Escuela Profesional de Genética y Biotecnología de la Universidad Nacional Mayor de San Marcos) for the invaluable scientific and humanistic formation provided to all authors.

\section{REFERENCES}

1. Zhu N, Zhang D, Wang W, Li X, Yang B, Song J, et al. A novel coronavirus from patients with pneumonia in China, 2019. N Engl J Med. (2020) 382:72733. doi: 10.1056/NEJMoa2001017

2. Coronaviridae Study Group of the International Committee on Taxonomy of Viruses. The species Severe acute respiratory syndrome-related coronavirus: classifying 2019-nCoV and naming it SARS-CoV-2. Nat Microbiol. (2020) 5:536-54. doi: 10.1038/s41564-020-0695-Z

3. World Health Organization. WHO Director-General's Opening Remarks at the Media Briefing on COVID-19 - 11 March 2020. (2020). Available online at: https://www.who.int/dg/speeches/detail/who-director-general-sopening-remarks-at-the-media-briefing-on-covid-19-\$-\$11-march-2020 (accessed April 5, 2020).

4. Lam TT, Shum MH, Zhu HC, Tong YG, Ni XB, Liao YS, et al. Identifying SARS-CoV-2 related coronaviruses in Malayan pangolins. Nature. (2020) 583:282-5. doi: 10.1101/2020.02.13.945485

5. Zhou P, Yang XL, Wang XG, Hu B, Zhang L, Zhang W, et al. A pneumonia outbreak associated with a new coronavirus of probable bat origin. Nature. (2020) 579:270-3. doi: 10.1038/s41586-020-2012-7

6. Wong ACP, Li X, Lau SKP, Woo PCY. Global epidemiology of bat coronaviruses. Viruses. (2019) 11:20174. doi: 10.3390/v11020174

7. Li W, Shi Z, Yu M, Ren W, Smith C, Epstein JH, et al. Bats are natural reservoirs of SARS-like coronaviruses. Science. (2005) 310:6769. doi: 10.1126/science.1118391

8. Ksiazek TG, Erdman D, Goldsmith CS, Zaki SR, Peret T, Emery S, et al. A novel coronavirus associated with severe acute respiratory syndrome. $N$ Engl J Med. (2003) 348:1953-66. doi: 10.1056/NEJMoa030781

9. Drosten C, Günther S, Preiser W, van der Werf S, Brodt HR, Becker S, et al. Identification of a novel coronavirus in patients with severe acute respiratory syndrome. N Engl J Med. (2003) 348:1967-76. doi: 10.1056/NEJMoa030747

10. Zaki AM, van Boheemen S, Bestebroer TM, Osterhaus AD, Fouchier RA. Isolation of a novel coronavirus from a man with pneumonia in Saudi Arabia. N Engl J Med. (2012) 367:1814-20. doi: 10.1056/NEJMoa1211721

11. Guan WJ, Ni ZY, Hu Y, Liang WH, Ou CQ, He JX, et al. Clinical Characteristics of Coronavirus Disease 2019 in China. N Engl J Med. (2020) 382:1708-20. doi: 10.1056/NEJMoa2002032

12. Huang C, Wang Y, Li X, Ren L, Zhao J, Hu Y, et al. Clinical features of patients infected with 2019 novel coronavirus in Wuhan, China. Lancet. (2020) 395:497-506. doi: 10.1016/S0140-6736(20)30183-5

13. Chan JF, Yuan S, Kok KH, To KK, Chu H, Yang J, et al. A familial cluster of pneumonia associated with the 2019 novel coronavirus indicating personto-person transmission: a study of a family cluster. Lancet. (2020) 395:51423. doi: 10.1016/S0140-6736(20)30154-9

14. Shereen MA, Khan S, Kazmi A, Bashir N, Siddique R. COVID-19 infection: Origin, transmission, and characteristics of human coronaviruses. J Adv Res. (2020) 24:91-8. doi: 10.1016/j.jare.2020.03.005

15. World Health Organization. Coronavirus disease (COVID-19) Pandemic. (2020). Available at: https://www.who.int/emergencies/diseases/novelcoronavirus-2019 (accessed May 15, 2020).

16. Zhao S, Lin Q, Ran J, Musa SS, Yang G, Wang W, et al. Preliminary estimation of the basic reproduction number of novel coronavirus $(2019-\mathrm{nCoV})$ in China, from 2019 to 2020: A data-driven analysis in the early phase of the outbreak. Int J Infect Dis. (2020) 92:214-7. doi: 10.1016/j.ijid.2020.01.050

17. Chan JF, Kok KH, Zhu Z, Chu H, To KK, Yuan S, et al. Genomic characterization of the 2019 novel human-pathogenic coronavirus isolated from a patient with atypical pneumonia after visiting Wuhan. Emerg Microbes Infect. (2020) 9:221-36. doi: 10.1080/22221751.2020.1719902

\section{SUPPLEMENTARY MATERIAL}

The Supplementary Material for this article can be found online at: https://www.frontiersin.org/articles/10.3389/fimmu. 2020.02008/full\#supplementary-material

18. Chen Y, Liu Q, Guo D. Emerging coronaviruses: genome structure, replication, and pathogenesis. J Med Virol. (2020) 92:418-23. doi: 10.1002/jmv.25681

19. Ceraolo C, Giorgi FM. Genomic variance of the 2019-nCoV coronavirus. J Med Virol. (2020) 92:522-8. doi: 10.1002/jmv.25700

20. Wu F, Zhao S, Yu B, Chen YM, Wang W, Song ZG, et al. A new coronavirus associated with human respiratory disease in China. Nature. (2020) 579:2659. doi: 10.1038/s41586-020-2008-3

21. Tai W, He L, Zhang X, Pu J, Voronin D, Jiang S, et al. Characterization of the receptor-binding domain (RBD) of 2019 novel coronavirus: implication for development of RBD protein as a viral attachment inhibitor and vaccine. Cell Mol Immunol. (2020) 17:613-20. doi: 10.1038/s41423-0200400-4

22. Walls AC, Park YJ, Tortorici MA, Wall A, McGuire AT, Veesler D. Structure, function, and antigenicity of the SARS-CoV-2 Spike glycoprotein. Cell. (2020) 181:281-92.e6. doi: 10.1016/j.cell.2020.02.058

23. Jeffers SA, Tusell SM, Gillim-Ross L, Hemmila EM, Achenbach JE, Babcock GJ, et al. CD209L (L-SIGN) is a receptor for severe acute respiratory syndrome coronavirus. Proc Natl Acad Sci USA. (2004) 101:1574853. doi: 10.1073/pnas.0403812101

24. Ulrich H, Pillat MM. CD147 as a target for COVID-19 treatment: suggested effects of azithromycin and stem cell engagement. Stem Cell Rev Rep. (2020) 16:434-40. doi: 10.1007/s12015-020-09976-7

25. Hoffmann M, Kleine-Weber H, Schroeder S, Krüger N, Herrler T, Erichsen $\mathrm{S}$, et al. SARS-CoV-2 cell entry depends on ACE2 and TMPRSS2 and is blocked by a clinically proven protease inhibitor. Cell. (2020) 181:27180.e8. doi: 10.1016/j.cell.2020.02.052

26. Shen S, Tan TH, Tan YJ. Expression, glycosylation, and modification of the spike (S) glycoprotein of SARS CoV. Methods Mol Biol. (2007) 379:12735. doi: 10.1007/978-1-59745-393-6_9

27. Petit CM, Chouljenko VN, Iyer A, Colgrove R, Farzan M, Knipe DM, et al. Palmitoylation of the cysteine-rich endodomain of the SARS-coronavirus spike glycoprotein is important for spike-mediated cell fusion. Virology. (2007) 360:264-74. doi: 10.1016/j.virol.2006.10.034

28. Chen SC, Lo SY, Ma HC, Li HC. Expression and membrane integration of SARS-CoV E protein and its interaction with M protein. Virus Genes. (2009) 38:365-71. doi: 10.1007/s11262-009-0341-6

29. Boscarino JA, Logan HL, Lacny JJ, Gallagher TM. Envelope protein palmitoylations are crucial for murine coronavirus assembly. J Virol. (2008) 82:2989-99. doi: 10.1128/JVI.01906-07

30. Voss D, Kern A, Traggiai E, Eickmann M, Stadler K, Lanzavecchia A, et al. Characterization of severe acute respiratory syndrome coronavirus membrane protein. FEBS Lett. (2006) 580:96873. doi: 10.1016/j.febslet.2006.01.026

31. Voss D, Pfefferle S, Drosten C, Stevermann L, Traggiai E, Lanzavecchia $\mathrm{A}$, et al. Studies on membrane topology, N-glycosylation and functionality of SARS-CoV membrane protein. Virol J. (2009) 6:79. doi: 10.1186/1743-422X-6-79

32. Surjit M, Kumar R, Mishra RN, Reddy MK, Chow VT, Lal SK. The severe acute respiratory syndrome coronavirus nucleocapsid protein is phosphorylated and localizes in the cytoplasm by 14-3-3-mediated translocation. J Virol. (2005) 79:11476-86. doi: 10.1128/JVI.79.17.11476-11486.2005

33. Grunewald ME, Fehr AR, Athmer J, Perlman S. The coronavirus nucleocapsid protein is ADP-ribosylated. Virology. (2018) 517:62-8. doi: 10.1016/j.virol.2017.11.020

34. Fung TS, Liu DX. Post-translational modifications of coronavirus proteins: roles and function. Futur Virol. (2018) 13:405-30. doi: 10.2217/fvl-2018-0008 
35. Ritchie G, Harvey DJ, Feldmann F, Stroeher U, Feldmann H, Royle $\mathrm{L}$, et al. Identification of $\mathrm{N}$-linked carbohydrates from severe acute respiratory syndrome (SARS) spike glycoprotein. Virology. (2010) 399:25769. doi: 10.1016/j.virol.2009.12.020

36. Balzarini J. Carbohydrate-binding agents: a potential future cornerstone for the chemotherapy of enveloped viruses? Antivir Chem Chemother. (2007) 18:1-11. doi: 10.1177/095632020701800101

37. Akerström S, Gunalan V, Keng CT, Tan YJ, Mirazimi A. Dual effect of nitric oxide on SARS-CoV replication: viral RNA production and palmitoylation of the S protein are affected. Virology. (2009) 395:19. doi: 10.1016/j.virol.2009.09.007

38. Holshue ML, DeBolt C, Lindquist S, Lofy KH, Wiesman J, Bruce H, et al. First Case of 2019 Novel Coronavirus in the United States. N Engl J Med. (2020) 382:929-36. doi: 10.1056/NEJMoa2001191

39. Corman VM, Landt O, Kaiser M, Molenkamp R, Meijer A, Chu DK, et al. Detection of 2019 novel coronavirus $(2019-\mathrm{nCoV})$ by real-time RT-PCR. Euro Surveill. (2020) 25:45. doi: 10.2807/1560-7917.ES.2020.25.3.2000045

40. To KK, Tsang OT, Chik-Yan Yip C, Chan KH, Wu TC, Chan JMC, et al. Consistent detection of 2019 novel coronavirus in saliva. Clin Infect Dis. (2020) 71:841-3. doi: 10.1093/cid/ciaa149

41. Liu W, Liu L, Kou G, Zheng Y, Ding Y, Ni W, et al. Evaluation of nucleocapsid and spike protein-based ELISAs for detecting antibodies against SARS-CoV2. J Clin Microbiol. (2020) 58:e00461-20. doi: 10.1128/JCM.00461-20

42. Zhang W, Du RH, Li B, Zheng XS, Yang XL, Hu B, et al. Molecular and serological investigation of $2019-\mathrm{nCoV}$ infected patients: implication of multiple shedding routes. Emerg Microbes Infect. (2020) 9:3869. doi: 10.1080/22221751.2020.1729071

43. Li Z, Yi Y, Luo X, Xiong N, Liu Y, Li S, et al. Development and clinical application of a rapid IgM-IgG combined antibody test for SARS-CoV-2 infection diagnosis. J Med Virol. (2020) 1-7. doi: 10.1002/jmv.25727

44. Okba NMA, Müller MA, Li W, Wang C, GeurtsvanKessel CH, Corman $\mathrm{VM}$, et al. Severe acute respiratory syndrome coronavirus 2-specific antibody responses in coronavirus disease 2019 patients. Emerg Infect Dis. (2020) 26:200841. doi: 10.3201/eid2607.200841

45. Broughton JP, Deng X, Yu G, Fasching CL, Servellita V, Singh J, et al. CRISPR-Cas12-based detection of SARS-CoV-2. Nat Biotechnol. (2020) 38:870-4. doi: 10.1038/s41587-020-0513-4

46. World Health Organization. Draft Landscape of COVID-19 Candidate Vaccines. (2020). Available online at: https://www.who.int/who-documentsdetail/draft-landscape-of-covid-19-candidate-vaccines (accessed May 8, 2020)

47. Thanh Le T, Andreadakis Z, Kumar A, Gómez Román R, Tollefsen S, Saville $\mathrm{M}$, et al. The COVID-19 vaccine development landscape. Nat Rev Drug Discov. (2020) 19:305-6. doi: 10.1038/d41573-020-00073-5

48. ClinicalTrials.gov. (2020). Available online at: https://clinicaltrials.gov/ (accessed April 11, 2020).

49. Flow Pharma FlowVax ${ }^{T M}$ Peptide Vaccine for COVID-19. (2020). Available online at: https://www.flowpharma.com/ (accessed April 11, 2020).

50. EPV-CoV19: HCW Vaccine. EpiVax, Inc - Informatics and Immunology. (2020). Available at: https://epivax.com/pipeline/epv-cov19 (accessed April 11, 2020).

51. IMV Inc. Launches Plans to Advance Clinical Development of a Vaccine Candidate Against COVID-19. (2020). Available online at: https://www.imvinc.com/news- events/press-releases/detail/645/imv-announces-selectionof-a-vaccine-candidate-against (accessed April 11, 2020).

52. Goren D. Vaxil Commences Preclinical Covid-19 Vaccine Trial and Files an Additional Covid-19 Patent. (2020). Available online at: https://vaxil-bio. com/vaxil-commences-preclinical-covid-19-vaccine-trial-and-files-anadditional-covid-19-patent/ (accessed April 11, 2020).

53. Bojin F, Gavriliuc O, Margineanu M-B, Paunescu V. Design of an EpitopeBased Synthetic Long Peptide Vaccine to Counteract the Novel China Coronavirus (2019- $n \mathrm{CoV}$ ) (2020). Available online at: https://www.preprints. org/manuscript/202002.0102/v1 (accessed April 11, 2020).

54. Saskatchewan Government Invests $\$ 3.6 M$ in USask COVID-19 Vaccine Research. Available online at: https://news.usask.ca/articles/research/2020/ saskatchewan-government-invests-3.6m-in-usask-covid-19-vaccineresearch.php (accessed April 11, 2020).

55. Backert L, Kohlbacher O. Immunoinformatics and epitope prediction in the age of genomic medicine. Genome Med. (2015) 7:119. doi: 10.1186/s13073-015-0245-0
56. Valdivia-Olarte H, Requena D, Ramirez M, Saravia LE, Izquierdo R, FalconiAgapito $\mathrm{F}$, et al. Design of a predicted $\mathrm{MHC}$ restricted short peptide immunodiagnostic and vaccine candidate for Fowl adenovirus $\mathrm{C}$ in chicken infection. Bioinformation. (2015) 11:460-5. doi: 10.6026/97320630011460

57. Morales Ruiz S, Bendezu J, Choque Guevara R, Montesinos R, Requena D, Choque Moreau L, et al. Development of a lateral flow test for the rapid detection of Avibacterium paragallinarum in chickens suspected of having infectious coryza. BMC Vet Res. (2018) 14:411. doi: 10.1186/s12917-018-1729-0

58. Zhao W, Sher X. Systematically benchmarking peptide-MHC binding predictors: From synthetic to naturally processed epitopes. PLoS Comput Biol. (2018) 14:e1006457. doi: 10.1371/journal.pcbi.1006457

59. Jurtz V, Paul S, Andreatta M, Marcatili P, Peters B, Nielsen M. NetMHCpan4.0: improved Peptide-MHC class i interaction predictions integrating eluted ligand and peptide binding affinity data. J Immunol. (2017) 199:33608. doi: 10.4049/jimmunol.1700893

60. O’Donnell TJ, Rubinsteyn A, Bonsack M, Riemer AB, Laserson U, Hammerbacher J. MHCflurry: open-source class I MHC binding affinity prediction. Cell Syst. (2018) 7:129-32.e4. doi: 10.1016/j.cels.2018.05.014

61. Reynisson B, Barra C, Kaabinejadian S, Hildebrand WH, Peters B, Nielsen M. Improved prediction of MHC II antigen presentation through integration and motif deconvolution of mass spectrometry MHC eluted ligand data. $J$ Proteome Res. (2020) 19:2304-15. doi: 10.1101/799882

62. Marsh SG, Albert ED, Bodmer WF, Bontrop RE, Dupont B, Erlich HA, et al. Nomenclature for factors of the HLA system, 2010. Tissue Antigens. (2010) 75:291-455. doi: 10.1111/j.1399-0039.2010.01466.x

63. Marsh SGE. WHO Nomenclature Committee for Factors of the HLA System. Nomenclature for factors of the HLA system. HLA. (2020) 95:599-637. doi: $10.1111 / \tan .13917$

64. Grifoni A, Sidney J, Zhang Y, Scheuermann RH, Peters B, Sette A. A Sequence homology and bioinformatic approach can predict candidate targets for immune responses to SARS-CoV-2. Cell Host Microbe. (2020) 27:671-80.e2. doi: 10.1016/j.chom.2020.03.002

65. Sidney J, Peters B, Frahm N, Brander C, Sette A. HLA class I supertypes: a revised and updated classification. BMC Immunol. (2008) 9:1. doi: 10.1186/1471-2172-9-1

66. Ahmed SF, Quadeer AA, McKay MR. Preliminary identification of potential vaccine targets for the COVID-19 Coronavirus (SARSCoV-2) based on SARS-CoV immunological studies. Viruses. (2020) 12:254. doi: 10.1101/2020.02.03.933226

67. Vita R, Mahajan S, Overton JA, Dhanda SK, Martini S, Cantrell JR, et al. The Immune Epitope Database (IEDB): 2018 update. Nucleic Acids Res. (2019) 47:D339-43. doi: 10.1093/nar/gky1006

68. Gonzalez-Galarza FF, McCabe A, Santos E, Jones J, Takeshita L, OrtegaRivera ND, et al. Allele frequency net database (AFND) 2020 update: gold-standard data classification, open access genotype data and new query tools. Nucleic Acids Res. (2020) 48:D783-8. doi: 10.1093/nar/ gkz1029

69. Flomenberg N, Baxter-Lowe LA, Confer D, Fernandez-Vina M, Filipovich A, Horowitz M, et al. Impact of HLA class I and class II high-resolution matching on outcomes of unrelated donor bone marrow transplantation: HLA-C mismatching is associated with a strong adverse effect on transplantation outcome. Blood. (2004) 104:1923-30. doi: 10.1182/blood-2004-03-0803

70. Chowell D, Morris LGT, Grigg CM, Weber JK, Samstein RM, Makarov V, et al. Patient HLA class I genotype influences cancer response to checkpoint blockade immunotherapy. Science. (2018) 359:582-7. doi: 10.1126/science.aao4572

71. Gutierrez-Arcelus M, Baglaenko Y, Arora J, Hannes S, Luo Y, Amariuta $\mathrm{T}$, et al. Allele-specific expression changes dynamically during $\mathrm{T}$ cell activation in HLA and other autoimmune loci. Nat Genet. (2020) 52:24753. doi: 10.1038/s41588-020-0579-4

72. Prinz JC. Human leukocyte antigen-class I alleles and the autoreactive $\mathrm{T}$ cell response in psoriasis pathogenesis. Front Immunol. (2018) 9:954. doi: 10.3389/fimmu.2018.00954

73. Elbe S, Buckland-Merrett G. Data, disease and diplomacy: GISAID's innovative contribution to global health. Glob Chall. (2017) 1:3346. doi: $10.1002 / \mathrm{gch} 2.1018$

74. Shannon CE. The mathematical theory of communication. 1963. MD Comput. (1997) 14:306-17. 
75. Afgan E, Baker D, Batut B, van den Beek M, Bouvier D, Cech $\mathrm{M}$, et al. The Galaxy platform for accessible, reproducible and collaborative biomedical analyses: 2018 update. Nucleic Acids Res. (2018) 46:W537-44. doi: 10.1093/nar/gky379

76. Marsh SG, Albert ED, Bodmer WF, Bontrop RE, Dupont B, Erlich HA, et al. An update to HLA nomenclature, 2010. Bone Marrow Transpl. (2010) 45:846-8. doi: 10.1038/bmt.2010.79

77. Moher D, Liberati A, Tetzlaff J, Altman DG, The PRISMA Group. Preferred reporting items for systematic reviews and meta-analyses: the PRISMA statement. PLoS Med. (2009) 6:e1000097. doi: 10.1371/journal.pmed1000097

78. Crooks GE, Hon G, Chandonia JM, Brenner SE. WebLogo: a sequence logo generator. Genome Res. (2004) 14:1188-90. doi: 10.1101/gr.849004

79. Zhang W-X, Pan X, Shen H-B. Signal-3L 3.0: improving signal peptide prediction through combining attention deep learning with window-based scoring. J Chem Inf Model. (2020) 60:3679-86. doi: 10.1021/acs.jcim.0c00401

80. Yin X, Yang J, Xiao F, Yang Y, Shen HB. MemBrain: an easy-to-use online webserver for transmembrane protein structure prediction. Nanomicro Lett. (2018) 10:2. doi: 10.1007/s40820-017-0156-2

81. Zhang M, Gaschen B, Blay W, Foley B, Haigwood N, Kuiken $\mathrm{C}$, et al. Tracking global patterns of N-linked glycosylation site variation in highly variable viral glycoproteins: HIV, SIV, and HCV envelopes and influenza hemagglutinin. Glycobiology. (2004) 14:1229-46. doi: 10.1093/glycob/cwh106

82. Steentoft C, Vakhrushev SY, Joshi HJ, Kong Y, Vester-Christensen MB, Schjoldager KT, et al. Precision mapping of the human O-GalNAc glycoproteome through SimpleCell technology. Embo J. (2013) 32:147888. doi: 10.1038/emboj.2013.79

83. Ren J, Wen L, Gao X, Jin C, Xue Y, Yao X. CSS-Palm 2.0: an updated software for palmitoylation sites prediction. Protein Eng Des Sel. (2008) 21:639-44. doi: 10.1093/protein/gzn039

84. Zhao Q, Xie Y, Zheng Y, Jiang S, Liu W, Mu W, et al. GPS-SUMO: a tool for the prediction of sumoylation sites and SUMO-interaction motifs. Nucleic Acids Res. (2014) 42:W325-30. doi: 10.1093/nar/gku383

85. Lo Monte M, Manelfi C, Gemei M, Corda D, Beccari AR. ADPredict: ADP-ribosylation site prediction based on physicochemical and structural descriptors. Bioinformatics. (2018) 34:2566-74. doi: 10.1093/bioinformatics/bty159

86. Waterhouse A, Bertoni M, Bienert S, Studer G, Tauriello G, Gumienny R, et al. SWISS-MODEL: homology modelling of protein structures and complexes. Nucleic Acids Res. (2018) 46:W296-303. doi: 10.1093/nar/gky427

87. Schrödinger LLC. The PyMOL Molecular Graphics System, Version 2.3. (2020). Available online at: https://pymol.org/2/support.html.

88. Hu Y, Wen J, Tang L, Zhang H, Zhang X, Li Y, et al. The M protein of SARS$\mathrm{CoV}$ : basic structural and immunological properties. Genomics Proteomics Bioinforma. (2003) 1:118-30. doi: 10.1016/S1672-0229(03)01016-7

89. Yuan Q, Liao Y, Torres J, Tam JP, Liu DX. Biochemical evidence for the presence of mixed membrane topologies of the severe acute respiratory syndrome coronavirus envelope protein expressed in mammalian cells. FEBS Lett. (2006) 580:3192-200. doi: 10.1016/j.febslet.2006.04.076

90. Schoeman D, Fielding BC. Coronavirus envelope protein: current knowledge. Virol J. (2019) 16:69. doi: 10.1186/s12985-019-1182-0

91. Le TM, Wong HH, Tay FP, Fang S, Keng CT, Tan YJ, et al. Expression, post-translational modification and biochemical characterization of proteins encoded by subgenomic mRNA8 of the severe acute respiratory syndrome coronavirus. Febs J. (2007) 274:4211-22. doi: 10.1111/j.1742-4658.2007.05947.x

92. Oostra M, de Haan CA, de Groot RJ, Rottier PJ. Glycosylation of the severe acute respiratory syndrome coronavirus triple-spanning membrane proteins 3a and M. J Virol. (2006) 80:2326-36. doi: 10.1128/JVI.80.5.2326-2336.2006

93. Shajahan A, Supekar NT, Gleinich AS, Azadi P. Deducing the N- and Oglycosylation profile of the spike protein of novel coronavirus SARS-CoV2. Glycobiology. (2020) cwaa042. doi: 10.1093/glycob/cwaa042. [Epub ahead of print].

94. Liao Y, Yuan Q, Torres J, Tam JP, Liu DX. Biochemical and functional characterization of the membrane association and membrane permeabilizing activity of the severe acute respiratory syndrome coronavirus envelope protein. Virology. (2006) 349:264-75. doi: 10.1016/j.virol. 2006.01 .028
95. McBride CE, Machamer CE. Palmitoylation of SARS-CoV S protein is necessary for partitioning into detergent-resistant membranes and cell-cell fusion but not interaction with M protein. Virology. (2010) 405:13948. doi: 10.1016/j.virol.2010.05.031

96. Lopez LA, Riffle AJ, Pike SL, Gardner D, Hogue BG. Importance of conserved cysteine residues in the coronavirus envelope protein. J Virol. (2008) 82:3000-10. doi: 10.1128/JVI.01914-07

97. Li FQ, Xiao H, Tam JP, Liu DX. Sumoylation of the nucleocapsid protein of severe acute respiratory syndrome coronavirus. FEBS Lett. (2005) 579:238796. doi: 10.1016/j.febslet.2005.03.039

98. Martini S, Nielsen M, Peters B, Sette A. The immune epitope database and analysis resource program 2003-2018: reflections and outlook. Immunogenetics. (2020) 72:57-76. doi: 10.1007/s00251-019-01137-6

99. Halagan M, Oliveira DC, Maiers M, Fabreti-Oliveira RA, Moraes $\mathrm{MEH}$, Visentainer JEL, et al. The distribution of HLA haplotypes in the ethnic groups that make up the Brazilian Bone Marrow Volunteer Donor Registry (REDOME). Immunogenetics. (2018) 70:51122. doi: 10.1007/s00251-018-1059-1

100. Vardhana SA, Wolchok JD. The many faces of the anti-COVID immune response. J Exp Med. (2020) 217:e20200678. doi: 10.1084/jem.20200678

101. Li CK, Wu H, Yan H, Ma S, Wang L, Zhang M, et al. T cell responses to whole SARS coronavirus in humans. J Immunol. (2008) 181:5490500. doi: 10.4049/jimmunol.181.8.5490

102. Leung DT, Tam FC, Ma CH, Chan PK, Cheung JL, Niu H, et al. Antibody response of patients with severe acute respiratory syndrome (SARS) targets the viral nucleocapsid. J Infect Dis. (2004) 190:379-86. doi: 10.1086/422040

103. He Y, Zhou Y, Siddiqui P, Niu J, Jiang S. Identification of immunodominant epitopes on the membrane protein of the severe acute respiratory syndrome-associated coronavirus. J Clin Microbiol. (2005) 43:371826. doi: 10.1128/JCM.43.8.3718-3726.2005

104. Du L, He Y, Zhou Y, Liu S, Zheng BJ, Jiang S. The spike protein of SARSCoV-a target for vaccine and therapeutic development. Nat Rev Microbiol. (2009) 7:226-36. doi: 10.1038/nrmicro2090

105. Zhou P, Han Z, Wang LF, Shi Z. Identification of immunogenic determinants of the spike protein of SARS-like coronavirus. Virol Sin. (2013) 28:926. doi: 10.1007/s12250-013-3292-y

106. Ying T, Du L, Ju TW, Prabakaran P, Lau CC, Lu L, et al. Exceptionally potent neutralization of Middle East respiratory syndrome coronavirus by human monoclonal antibodies. J Virol. (2014) 88:7796-805. doi: 10.1128/JVI.00912-14

107. Muthumani K, Falzarano D, Reuschel EL, Tingey C, Flingai S, Villarreal DO, et al. A synthetic consensus anti-spike protein DNA vaccine induces protective immunity against Middle East respiratory syndrome coronavirus in nonhuman primates. Sci Transl Med. (2015) 7:301ra132. doi: 10.1126/scitranslmed.aac7462

108. Wang Q, Zhang L, Kuwahara K, Li L, Liu Z, Li T, et al. Immunodominant SARS coronavirus epitopes in humans elicited both enhancing and neutralizing effects on infection in non-human primates. ACS Infect Dis. (2016) 2:361-76. doi: 10.1021/acsinfecdis.6b00006

109. Yang ZY, Kong WP, Huang Y, Roberts A, Murphy BR, Subbarao K, et al. A DNA vaccine induces SARS coronavirus neutralization and protective immunity in mice. Nature. (2004) 428:561-4. doi: 10.1038/nature02463

110. Yan R, Zhang Y, Li Y, Xia L, Guo Y, Zhou Q. Structural basis for the recognition of SARS-CoV-2 by full-length human ACE2. Science. (2020) 367:1444-8. doi: 10.1126/science.abb2762

111. Tian X, Li C, Huang A, Xia S, Lu S, Shi Z, et al. Potent binding of 2019 novel coronavirus spike protein by a SARS coronavirus-specific human monoclonal antibody. Emerg Microbes Infect. (2020) 9:3825. doi: 10.1080/22221751.2020.1729069

112. Yuan M, Wu NC, Zhu X, Lee CD, So RTY, Lv H, et al. A highly conserved cryptic epitope in the receptor binding domains of SARS-CoV-2 and SARSCoV. Science. (2020) 368:630-3. doi: 10.1126/science.abb7269

113. ter Meulen J, van den Brink EN, Poon LL, Marissen WE, Leung CS, Cox F, et al. Human monoclonal antibody combination against SARS coronavirus: synergy and coverage of escape mutants. PLoS Med. (2006) 3:e237. doi: 10.1371/journal.pmed.0030237

114. Elshabrawy HA, Coughlin MM, Baker SC, Prabhakar BS. Human monoclonal antibodies against highly conserved HR1 and HR2 domains 
of the SARS-CoV spike protein are more broadly neutralizing. PLoS ONE. (2012) 7:e50366. doi: 10.1371/journal.pone.0050366

115. Prabakaran P, Gan J, Feng Y, Zhu Z, Choudhry V, Xiao X, et al. Structure of severe acute respiratory syndrome coronavirus receptor-binding domain complexed with neutralizing antibody. J Biol Chem. (2006) 281:1582936. doi: $10.1074 / j b c . M 600697200$

116. Sui J, Li W, Murakami A, Tamin A, Matthews LJ, Wong SK, et al. Potent neutralization of severe acute respiratory syndrome (SARS) coronavirus by a human $\mathrm{mAb}$ to $\mathrm{S} 1$ protein that blocks receptor association. Proc Natl Acad Sci USA. (2004) 101:2536-41. doi: 10.1073/pnas.0307140101

117. Yu X, Zhang S, Jiang L, Cui Y, Li D, Wang D, et al. Structural basis for the neutralization of MERS-CoV by a human monoclonal antibody MERS-27. Sci Rep. (2015) 5:13133. doi: 10.1038/srep13133

118. Li Y, Wan Y, Liu P, Zhao J, Lu G, Qi J, et al. A humanized neutralizing antibody against MERS-CoV targeting the receptor-binding domain of the spike protein. Cell Res. (2015) 25:1237-49. doi: 10.1038/cr.2015.113

119. Yuan Y, Cao D, Zhang Y, Ma J, Qi J, Wang Q, et al. Cryo-EM structures of MERS-CoV and SARS-CoV spike glycoproteins reveal the dynamic receptor binding domains. Nat Commun. (2017) 8:15092. doi: 10.1038/ncomms15092

120. Yuan K, Yi L, Chen J, Qu X, Qing T, Rao X, et al. Suppression of SARS-CoV entry by peptides corresponding to heptad regions on spike glycoprotein. Biochem Biophys Res Commun. (2004) 319:74652. doi: 10.1016/j.bbrc.2004.05.046

121. Liu IJ, Kao CL, Hsieh SC, Wey MT, Kan LS, Wang WK. Identification of a minimal peptide derived from heptad repeat (HR) 2 of spike protein of SARS-CoV and combination of HR1-derived peptides as fusion inhibitors. Antivir Res. (2009) 81:82-7. doi: 10.1016/j.antiviral.2008.10.001

122. Gao J, Lu G, Qi J, Li Y, Wu Y, Deng Y, et al. Structure of the fusion core and inhibition of fusion by a heptad repeat peptide derived from the $S$ protein of Middle East respiratory syndrome coronavirus. J Virol. (2013) 87:13134-40. doi: 10.1128/JVI.02433-13

123. Channappanavar R, Lu L, Xia S, Du L, Meyerholz DK, Perlman S, et al. Protective effect of intranasal regimens containing peptidic middle east respiratory syndrome coronavirus fusion inhibitor against MERS-CoV infection. J Infect Dis. (2015) 212:1894-903. doi: 10.1093/infdis/jiv325

124. Chacón RD, Astolfi-Ferreira CS, Chacón JL, Nuñez LFN, De la Torre DI, Piantino Ferreira AJ. A seminested RT-PCR for molecular genotyping of the Brazilian BR-I Infectious Bronchitis Virus Strain (GI-11). Mol Cell Probes. (2019) 47:101426. doi: 10.1016/j.mcp.2019.101426

125. Purohit HJ, Raje D V, Kapley A. Identification of signature and primers specific to genus Pseudomonas using mismatched patterns of 16S rDNA sequences. BMC Bioinformatics. (2003) 4:19. doi: 10.1186/1471-2105-4-19

126. Rossen JW, de Beer R, Godeke GJ, Raamsman MJ, Horzinek MC, Vennema $\mathrm{H}$, et al. The viral spike protein is not involved in the polarized sorting of coronaviruses in epithelial cells. J Virol. (1998) 72:497503. doi: 10.1128/JVI.72.1.497-503.1998

127. Yang Y, Liu C, Du L, Jiang S, Shi Z, Baric RS, et al. Two mutations were critical for bat-to-human transmission of middle east respiratory syndrome coronavirus. J Virol. (2015) 89:9119-23. doi: 10.1128/JVI.01279-15

128. Pallesen J, Wang N, Corbett KS, Wrapp D, Kirchdoerfer RN, Turner HL, et al. Immunogenicity and structures of a rationally designed prefusion MERS-CoV spike antigen. Proc Natl Acad Sci USA. (2017) 114:E734857. doi: 10.1073/pnas.1707304114

129. Walls AC, Xiong X, Park YJ, Tortorici MA, Snijder J, Quispe J, et al. Unexpected receptor functional mimicry elucidates activation of coronavirus fusion. Cell. (2019) 176:1026-39.e15. doi: 10.1016/j.cell.2018.12.028

130. Xiong X, Tortorici MA, Snijder J, Yoshioka C, Walls AC, Li W, et al. Glycan shield and fusion activation of a deltacoronavirus spike glycoprotein fine-tuned for enteric infections. J Virol. (2018) 92:e01628-17. doi: 10.2210/pdb6bfu/pdb

131. Carranza C, Astolfi-Ferreira CS, Santander Parra SH, Nuñez LFN, Penzes Z, Chacón JL, et al. Genetic characterisation and analysis of infectious bronchitis virus isolated from Brazilian flocks between 2010 and 2015. $\mathrm{Br}$ Poult Sci. (2017) 58:610-23. doi: 10.1080/00071668.2017.1365116

132. Watanabe Y, Allen JD, Wrapp D, McLellan JS, Crispin M. Sitespecific glycan analysis of the SARS-CoV-2 spike. Science. (2020) 369:330-3. doi: 10.1126/science.abb9983
133. Han DP, Lohani M, Cho MW. Specific asparagine-linked glycosylation sites are critical for DC-SIGN- and L-SIGN-mediated severe acute respiratory syndrome coronavirus entry. J Virol. (2007) 81:1202939. doi: 10.1128/JVI.00315-07

134. Feinberg H, Mitchell DA, Drickamer K, Weis WI. Structural basis for selective recognition of oligosaccharides by DC-SIGN and DC-SIGNR. Science. (2001) 294:2163-6. doi: 10.1126/science.1066371

135. Chakraborti S, Prabakaran P, Xiao X, Dimitrov DS. The SARS coronavirus $S$ glycoprotein receptor binding domain: fine mapping and functional characterization. Virol J. (2005) 2:73. doi: 10.1186/1743-422X-2-73

136. Shih YP, Chen CY, Liu SJ, Chen KH, Lee YM, Chao YC, et al. Identifying epitopes responsible for neutralizing antibody and DC-SIGN binding on the spike glycoprotein of the severe acute respiratory syndrome coronavirus. $J$ Virol. (2006) 80:10315-24. doi: 10.1128/JVI.01138-06

137. Marzi A, Gramberg T, Simmons G, Möller P, Rennekamp AJ, Krumbiegel M, et al. DC-SIGN and DC-SIGNR interact with the glycoprotein of Marburg virus and the $\mathrm{S}$ protein of severe acute respiratory syndrome coronavirus. $J$ Virol. (2004) 78:12090-5. doi: 10.1128/JVI.78.21.12090-12095.2004

138. Andersen KG, Rambaut A, Lipkin WI, Holmes EC, Garry RF. The proximal origin of SARS-CoV-2. Nat Med. (2020) 26:450-2. doi: 10.1038/s41591-020-0820-9

139. Wrapp D, Wang N, Corbett KS, Goldsmith JA, Hsieh CL, Abiona O, et al. Cryo-EM structure of the 2019-nCoV spike in the prefusion conformation. Science. (2020) 367:1260-3. doi: 10.1126/science.abb2507

140. Walls AC, Tortorici MA, Frenz B, Snijder J, Li W, Rey FA, et al. Glycan shield and epitope masking of a coronavirus spike protein observed by cryo-electron microscopy. Nat Struct Mol Biol. (2016) 23:899905. doi: 10.1038/nsmb.3293

141. Watanabe Y, Bowden TA, Wilson IA, Crispin M. Exploitation of glycosylation in enveloped virus pathobiology. Biochim Biophys Acta Gen Subj. (2019) 1863:1480-97. doi: 10.1016/j.bbagen.2019.05.012

142. Bos EC, Heijnen L, Luytjes W, Spaan WJ. Mutational analysis of the murine coronavirus spike protein: effect on cell-to-cell fusion. Virology. (1995) 214:453-63. doi: 10.1006/viro.1995.0056

143. Shulla A, Gallagher T. Role of spike protein endodomains in regulating coronavirus entry. J Biol Chem. (2009) 284:3272534. doi: 10.1074/jbc.M109.043547

144. Thorp EB, Boscarino JA, Logan HL, Goletz JT, Gallagher TM. Palmitoylations on murine coronavirus spike proteins are essential for virion assembly and infectivity. J Virol. (2006) 80:1280-9. doi: 10.1128/JVI.80.3.1280-1289.2006

145. Gelhaus S, Thaa B, Eschke K, Veit M, Schwegmann-Wessels C. Palmitoylation of the Alphacoronavirus TGEV spike protein S is essential for incorporation into virus-like particles but dispensable for S-M interaction. Virology. (2014) 464-465:397-405. doi: 10.1016/j.virol.2014.07.035

146. Zhong J, Tang J, Ye C, Dong L. The immunology of COVID-19: is immune modulation an option for treatment? Lancet Rheumatol. (2020) 2:e42836. doi: 10.1016/S2665-9913(20)30120-X

147. Cummings MJ, Baldwin MR, Abrams D, Jacobson SD, Meyer BJ, Balough EM, et al. Epidemiology, clinical course, and outcomes of critically ill adults with COVID-19 in New York City: a prospective cohort study. Lancet. (2020) 395:1763-70. doi: 10.1016/S0140-6736(20)31189-2

148. Ellinghaus D, Degenhardt F, Bujanda L, Buti M, Albillos A, Invernizzi P, et al. Genomewide association study of severe covid-19 with respiratory failure. $N$ Engl J Med. (2020). doi: 10.1056/NEJMoa2020283. [Epub ahead of print].

Conflict of Interest: The authors declare that the research was conducted in the absence of any commercial or financial relationships that could be construed as a potential conflict of interest.

Copyright $\odot 2020$ Requena, Médico, Chacón, Ramírez and Marin-Sánchez. This is an open-access article distributed under the terms of the Creative Commons Attribution License (CC BY). The use, distribution or reproduction in other forums is permitted, provided the original author(s) and the copyright owner(s) are credited and that the original publication in this journal is cited, in accordance with accepted academic practice. No use, distribution or reproduction is permitted which does not comply with these terms. 